\title{
Otolith-based approaches indicate strong effects of environmental variation on growth of a Critically Endangered estuarine fish
}

\author{
Levi S. Lewis ${ }^{1, *}$, Christian Denney ${ }^{1}$, Malte Willmes ${ }^{1,2}$, Wilson Xieu ${ }^{1}$, \\ Rachel A. Fichman ${ }^{1}$, Feng Zhao ${ }^{1}$, Bruce G. Hammock ${ }^{3}$, Andrew Schultz ${ }^{4}$, Nann \\ Fangue $^{1}$, James A. Hobbs ${ }^{1,5}$

\begin{abstract}
${ }^{1}$ Wildlife, Fish and Conservation Biology, University of California, Davis, 1 Shields Ave, Davis, CA 95616, USA
${ }^{2}$ Institute of Marine Sciences/NOAA Fisheries Collaborative Program, University of California, Santa Cruz, 156 High Street, Santa Cruz, CA 95064, USA

${ }^{3}$ Cell Biology, School of Veterinary Medicine, University of California, 1089 Veterinary Medicine Drive, VetMed 3B, Davis, CA 95616, USA
\end{abstract} \\ ${ }^{4}$ US Bureau of Reclamation Bay-Delta Office, Science Division, $9809^{\text {th }}$ St., Sacramento, CA 95814, USA \\ ${ }^{5}$ California Department of Fish and Wildlife, 2109Arch Airport Road, Suite 100, Stockton, CA 95206, USA
}

\begin{abstract}
In estuaries, fluctuating environmental conditions exact strenuous physiological demands on the fishes that inhabit these oft-impacted areas, including the Critically Endangered delta smelt Hypomesus transpacificus in California (USA). Using an archive of otoliths spanning 2011-2019, we examined how growth rates of wild subadult delta smelt vary ontogenetically, regionally, and in relation to variation in the physical environment during late-summer and fall in the upper San Francisco Estuary. Recent growth rates were quantified using otolith increment analysis and modeled as functions of both intrinsic (age) and extrinsic (temperature, salinity, clarity, and region) factors using a suite of generalized additive models. Age explained $60 \%$ of the variation in $\log _{10}$-transformed growth rates, which peaked at 50-80 d post hatch. Overall, ageadjusted growth rates declined at temperatures $>20^{\circ} \mathrm{C}$, increased with practical salinity values of $0-4$, and exhibited interactive patterns with water clarity. Growth rates appeared highest in the West and Central Delta, and lowest in the North Delta, also corresponding with patterns in environmental conditions. Here, we provide new evidence for how vital rates of wild delta smelt vary spatially and in relation to abiotic environmental variation. Such otolith-based growth reconstructions often provide the first direct look at how the vital rates of wild fish respond to environmental variation in situ, and how future changes are likely to affect the dynamics of wild populations.
\end{abstract}

KEY WORDS: Delta smelt · Hypomesus transpacificus · Water quality · Climate - Salinity · Temperature $\cdot$ Turbidity $\cdot$ Generalized additive model $\cdot$ Biological intercept

\section{INTRODUCTION}

Intersections among structural and dynamic features in estuaries largely determine their suitability for the growth, survival, and production of estuarine fishes (Beck et al. 2001, Peterson 2003, Niklitschek \& Secor 2009, Nagelkerken et al. 2015). Dynamic estu-

\footnotetext{
*Corresponding author: lewis.sci@gmail.com
}

arine gradients in water quality (e.g. temperature, salinity, and clarity) vary in response to natural variation in climatic and oceanographic drivers that affect local patterns in precipitation, air temperature, wind, and upwelling. However, anthropogenic changes to the climate and local hydrology of estuaries can also alter these gradients, thus impacting habitat suitabil(c) L.S.L., C.D., M.W., W.X., R.A.F., F.Z., B.G.H. N.F., J.A.H., and outside the USA, the US Government 2021. Open Access under Creative Commons by Attribution Licence. Use, distribution and reproduction are unrestricted. Authors and original publication must be credited.

Publisher: Inter-Research · www.int-res.com 
ity for estuarine species (Gillanders et al. 2011, Brown et al. 2013, 2016, James et al. 2013, Robins et al. 2016, Muhling et al. 2018). For example, temperature increases metabolic rates and subsequent growth rates (Jain \& Farrell 2003, Green \& Fisher 2004) until thermal limits are reached, after which growth is suppressed (Houde 1989, Pörtner \& Farrell 2008, Neuheimer et al. 2011, Wenger et al. 2016, Dahlke et al. 2020, Neubauer \& Andersen 2020). Similarly, changes in salinity can influence metabolic demands, contingent upon the osmoregulatory physiology of a given species (Lankford \& Targett 1994, Baltz et al. 1998, Labonne et al. 2009, Komoroske et al. 2016), and turbidity can enhance growth and survival by reducing predation risk and enhancing foraging success of larval fishes (Blaber \& Blaber 1980, Cyrus \& Blaber 1987, 1992, Gregory 1993, Rypel et al. 2007, Tigan et al. 2020). Suitable habitat, therefore, can become limiting when anthropogenic modifications uncouple key structural (e.g. habitat) and dynamic (e.g. water quality) features of estuaries that affect the growth, survival, and recruitment of fishes.

The delta smelt Hypomesus transpacificus is a pelagic osmerid fish that is endemic to the tidal fresh and low-salinity waters of the upper San Francisco

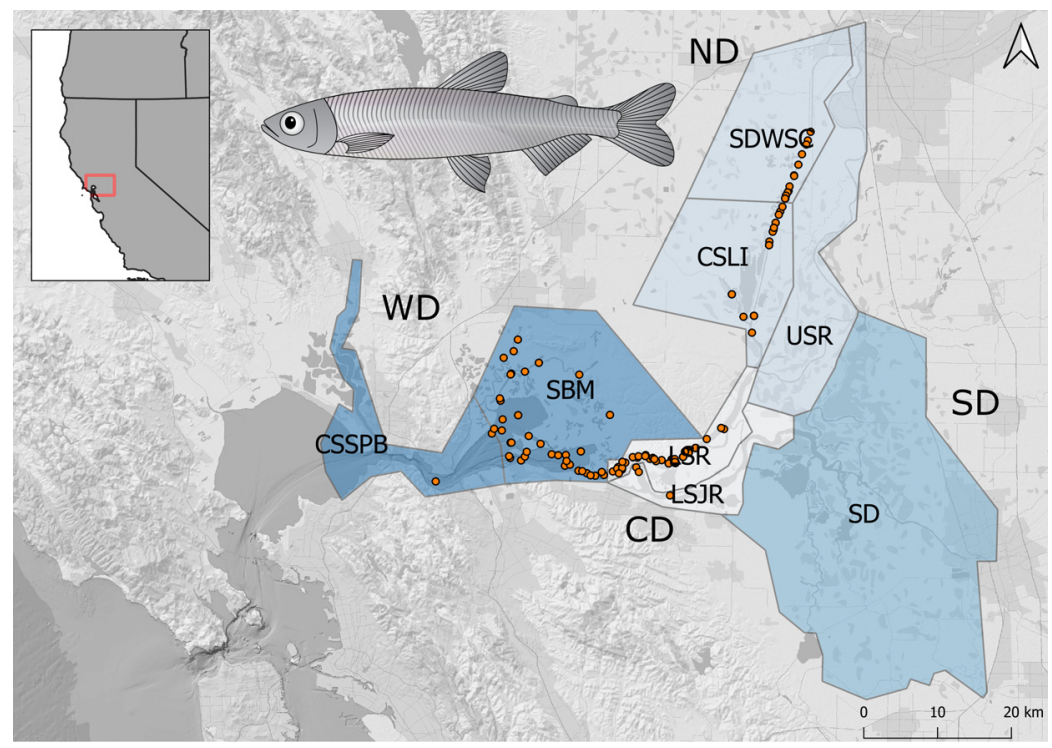

Fig. 1. Upper San Francisco Estuary (SFE). Polygons indicate subregions; CSSPB: Carquinez Strait and San Pablo Bay; SBM: Suisun Bay and Marsh; LSR: Lower Sacramento River; LSJR: Lower San Joaquin River; CSLI: Cache Slough and Liberty Island; SDWSC: Sacramento Deep Water Shipping Channel; USR: Upper Sacramento River; SD: South Delta. Strata of similar shades represent broader regions: West Delta (WD), Central Delta (CD), North Delta (ND), and SD (Table 1). All specimens included in this study were collected in the WD, CD, and ND regions of the SFE (orange circles). Subregions adapted from the Enhanced Delta Smelt Monitoring 2017 Survey 'strata' (Text S1 in Supplement 1 at www.int-res.com/articles/suppl/m676p037_supp.pdf). Delta smelt artwork by Adi Khen
Estuary (SFE), California (USA), including openwater, slough, and wetland habitats of Suisun Bay and the Sacramento-San Joaquin River Delta (hereafter 'Delta') (Moyle et al. 1992, 2016, Hobbs et al. 2019) (Fig. 1). As a result of precipitous population eclines since the 1980s (Mac Nally et al. 2010, homson et al. 2010, Hobbs et al. 2017), delta smelt re currently listed as threatened, endangered, and itically Endangered according to federal, state, nd international population status assessments, repectively (US Fish and Wildlife Service 1993, CDFG 10, NatureServe 2014). Though not yet extinct, seval long-term surveys have failed to detect even a ngle fish over the last 3 years. Multiple factors have ely contributed to this decline, including hydrologalterations, habitat degradation, non-native comand predator species, agricultural and municexports (Knowles \& Cayan 2002, Bennett 2005, al. 2007, Cloern \& Jassby 2012, Fong et al. , Moyle et al. 2016, 2018, Smith et al. 2020). Conwave occasionally impacted freshwater deliveries to California's multi-billion-dollar agriculture industry and 29 million southern residents, thus putting this endangered species in the political crossfire between advocates of species conservation versus those focused on water conveyance and agriculture (Feyrer et al. 2011, Moyle et al. 2018, Reis et al. 2019, Scoville 2019). In order to effectively manage the system for water conveyance while also protecting sensitive species such as delta smelt, an understanding of how species respond to natural and anthropogenic variation in environmental conditions is needed.

The responses of species to environmental variation (e.g. temperature, salinity, and clarity) are often assessed empirically using distribution models based on field survey data (e.g. occupancy modeling) or mechanistically using controlled laboratory studies. Based on field surveys, delta smelt are typically captured at temperatures $<25^{\circ} \mathrm{C}$, practical salinities $<15$, and clarity (Secchi depth) <0.25 m (Bennett 2005, Feyrer et al. 2007, Nobriga et al. 2008, Komoroske et al. 2014). Similarly, acute critical thermal maxima of cultured delta smelt in laboratory experiments range from 24 to $30^{\circ} \mathrm{C}$, depending on 
acclimation temperature and ontogenetic stage (Komoroske et al. 2014), and sublethal physiological stress responses can be elicited at temperatures as low as $23^{\circ} \mathrm{C}$ (Komoroske et al. 2015, 2016). For younger life stages, foraging activity and success in cultured delta smelt are generally maximized at lowlight levels and higher turbidities of 18-80 nephelometer turbidity units (NTU) (Lindberg et al. 2013, Tigan et al. 2020). Foraging by older life stages, however, may be less sensitive to turbidity and even reduced at very high (e.g. >80 NTU) turbidity values (Hasenbein et al. 2013, Hammock et al. 2019).

Although field-occupancy and laboratory studies of cultured fish are valuable and informative, it remains important to address likely limitations of these studies for understanding the responses of wild delta smelt to variation in the abiotic environment, in situ. In surveys, fish may often occur in lower-quality habitats, especially if they cannot detect or move freely across suitability gradients. Thus, empirical habitat suitability models based on occurrence may be insensitive to sublethal physiological effects of stressors on fish condition and population dynamics. Similarly, acute mechanistic thresholds established by short-term laboratory experiments using cultured fish may not account for the importance of chronic exposures to sublethal levels of stress, or complex interactions in situ, and thus may also mischaracterize the responses of wild populations to environmental patterns (Speers-Roesch \& Norin 2016, Morgan et al. 2019). To address these limitations, studies examining the biological responses of wild specimens to variation in ambient environmental conditions are needed.

Growth is a key vital rate in the early life stages of fishes that integrates their physiological responses to environmental variation. Rapid growth corresponds with increased survival due to enhanced predator avoidance and prey capture. Therefore, given the high mortality rates experienced by early life-stages of fishes, small differences in growth and survival rates can lead to large variation in recruitment and year-class strength (Hjort 1914, Anderson 1988, Houde 1989, Cushing 1990). In annual fishes, such as delta smelt, poor growth corresponds with delayed maturity, lower fecundity, higher mortality, and reduced population growth (Bennett 2005, Rose et al. 2013a,b, Damon et al. 2016). Growth rate can therefore be used as a biologically meaningful metric for assessing habitat suitability for wild specimens in their natural habitats. By understanding how environmental conditions influence the growth rates of wild fish populations, we can more confidently assess how human activities are likely to impact their dynamics.

A powerful tool for assessing the growth rates of wild fishes is otolith microstructural analysis (Pannella 1971). Otoliths ('ear stones') are bone-like structures found in the inner ear of fishes that are used for hearing and balance. They are formed by the accretion of calcium carbonate and proteins around a primordium, creating daily light and dark bands (increments) that can be used to estimate age for early life stages of fishes. Since otolith accretion is often correlated with somatic growth (Campana \& Jones 1992), the widths of daily increments can also be used to reconstruct the growth history of individual fish. Such otolith-based approaches have been previously validated and applied to delta smelt to describe their life history and the timing of migrations (Hobbs et al. 2007, 2019).

To enhance our understanding of how wild delta smelt respond to natural and anthropogenic variation in their physical environment, we examined otolithbased growth rates among regions and as functions of water quality (salinity, temperature, and clarity) in the upper SFE. We then contrasted patterns in the vital rates of the wild population with existing hypotheses based on occupancy and laboratory studies which indicate upper water temperature thresholds of 24$25^{\circ} \mathrm{C}$ due to thermal stress (Feyrer et al. 2007, Komoroske et al. 2015), optimal growth conditions at practical salinities of 1-4 where osmoregulatory stress is limited and foraging is enhanced (Komoroske et al. 2016, Hammock et al. 2017), and varying effects of water clarity (Hasenbein et al. 2013, Tigan et al. 2020). By contrasting the responses of wild individuals with predictions based on previous models, we aimed to verify or modify our current understanding of habitat suitability, population dynamics, and the most promising options for conserving this Critically Endangered species.

\section{MATERIALS AND METHODS}

\subsection{Study site}

The SFE is the largest coastal estuary in California, characterized by an 'upper estuary' which receives the majority of freshwater inputs from the Sacramento River and San Joaquin River watersheds that each flow into the North and South Delta, respectively (Fig. 1). The 2 rivers meet at their confluence in the Central Delta and are tidally mixed downstream into the more brackish waters of the West Delta, and 
eventually out into the saltier bays of the lower estuary. The estuary is a 'radically transformed' ecosystem serving 7.5 million local residents, a large commercial shipping industry, several coastal fisheries, and is the final destination of 50 municipal sewage treatment plants (Cloern \& Jassby 2012). Over 95\% of its tidal marsh habitats have been degraded, and its hydrograph has been highly altered. Over $100 \%$ of the mean annual rainfall can be captured behind major dams that exist on most tributaries, and over $30 \%$ of the freshwater flowing into the estuary is diverted annually by state and federal pumping facilities to support agricultural and municipal needs in the southern part of the state, thus impacting the many species that live within or migrate through the upper estuary. To monitor the ecological effects of these anthropogenic alterations, several long-term state and federal monitoring programs have been established, each yielding detailed records of fish abundances, environmental conditions, and historical archives of specimens that can be analyzed by researchers to better inform management and policy decisions (Text S1 in Supplement 1 at www.int-res. com/articles/suppl/m676p037_supp.pdf).

Environmental conditions in the SFE are highly dynamic. In general, the estuary exhibits a salinity gradient from freshwater upstream habitats in the North and South Delta to low-salinity (e.g. practical salinities of 1-10) brackish habitats in the West Delta, with variable conditions between in the Central Delta. Freshwater inflow and spatial salinity gradients vary seasonally, marked primarily by wet winters and dry summers (Cloern \& Jassby 2012). Similarly, water temperatures and clarity vary spatially and seasonally, with temperatures varying by more than $20^{\circ} \mathrm{C}$ and water clarity varying from $\mathrm{cm}$ to several meters in Secchi depth. Native species, such as delta smelt, have evolved to cope with these dynamic physical attributes; however, anthropogenic alterations to the hydrograph and local climate are increasingly compressing the quality and quantity of habitats available to native species (Cloern et al. 2011). For example, as the estuary continues to warm, thermal stress is likely to increasingly impact the population dynamics of delta smelt (Brown et al. 2016). Reductions in freshwater outflow due to diversions, combined with sea level rise due to climate change, are likely to push salinity gradients further inland, reducing the amount of low-salinity habitat, and further exacerbating warming trends (Nobriga et al. 2008, Feyrer et al. 2011, Brown et al. 2016). Continuing increases in water clarity due to sediment capture by dams and expanding aquatic vegetation, as well as changes in weather patterns, are also likely to impact turbidityseeking species such as delta smelt (Hestir et al. 2016, Bever et al. 2018). Improved understandings of relationships between species and environmental conditions can yield better predictions about the likely impacts of future environmental change, as well as the responses of species to specific water management and conservation actions.

\subsection{Sample collection and processing}

We used a long-term archive of wild delta smelt otoliths to explore variation in growth rate in relation to the region and environmental conditions at capture. Wild delta smelt of $51.2 \pm 6.8 \mathrm{~mm}$ (mean $\pm \mathrm{SD}$ ) fork length were collected throughout their range during August-November of 2011-2019 (Fig. 1, Table 1) by several long-term monitoring programs and special studies conducted by the California Department of Fish and Wildlife (CDFW) and US Fish and Wildlife Service (Text S1 and Tables S1-S3 in Supplement 1). This time period and life stage were

Table 1. Total delta smelt $(\mathrm{N}=459)$ included in the study by year, region, and subregion (Enhanced Delta Smelt Monitoring 2017 'strata'). Regions and subregions are ordered from upstream (top) to downstream (bottom): ND: North Delta, SD: South Delta, CD: Central Delta, WD: West Delta (Fig. 1)

\begin{tabular}{|c|c|c|c|c|c|c|c|c|c|c|c|c|}
\hline Region & Subregion & $\begin{array}{l}\text { Subregion } \\
\text { code }\end{array}$ & 2011 & 2012 & 2013 & 2014 & 2015 & 2016 & 2017 & 2018 & 2019 & Total \\
\hline ND & Cache Slough and Liberty Isl. & CSLI & 15 & 6 & 1 & 21 & 2 & 0 & 0 & 32 & 1 & 78 \\
\hline ND & $\begin{array}{l}\text { Sacramento Deep Water } \\
\text { Shipping Channel }\end{array}$ & SDWSC & 0 & 0 & 0 & 0 & 0 & 0 & 2 & 27 & 1 & 30 \\
\hline $\mathrm{CD}$ & Lower Sacramento River & LSR & 5 & 62 & 43 & 72 & 22 & 3 & 36 & 17 & 2 & 262 \\
\hline $\mathrm{CD}$ & Lower San Joaquin River & LSJR & 0 & 0 & 2 & 0 & 0 & 0 & 1 & 0 & 0 & 3 \\
\hline WD & Suisun Bay and Marsh & SBM & 34 & 4 & 0 & 0 & 0 & 0 & 33 & 6 & 4 & 81 \\
\hline \multirow[t]{2}{*}{ WD } & Carquinez Strait \& San Pablo Bay & CSSPB & 5 & 0 & 0 & 0 & 0 & 0 & 0 & 0 & 0 & 5 \\
\hline & & Total & 59 & 72 & 46 & 93 & 24 & 3 & 72 & 82 & 8 & 459 \\
\hline
\end{tabular}


selected because they represent a critical period in the life cycle of this fish, when environmental variation is likely to influence vital rates such as individual growth, fecundity, and subsequent population growth (Rose et al. 2013b), and when management actions (e.g. flow augmentation) have been focused to improve environmental conditions to help restore the delta smelt population. During surveys, each fish was generally given a unique serial number upon capture, its fork length measured to the nearest $1 \mathrm{~mm}$, and its body preserved in either $95 \%$ ethanol or liquid nitrogen. If a field fork length could not be identified, it was estimated using standard conversion equations for ethanol or liquid nitrogen-preserved specimens (Text S1).

Water quality parameters, including temperature $\left({ }^{\circ} \mathrm{C}\right)$, practical salinity (calculated from specific conductance in $\mu \mathrm{S} \mathrm{cm}^{-1}$ ), and Secchi depth (m), were measured during each collection event using standard practices. Temperature and specific conductance were measured by each survey using boat-deployed sondes (e.g. YSI Pro30 or a Sea-Bird Scientific CTD), and salinity was calculated from specific conductance using standard equations for low (0-2) and high (2-42) practical salinity values (Lewis \& Perkin 1981, Hill et al. 1986). Water transparency (clarity, in $\mathrm{cm}$ ) was measured using a standard $20 \mathrm{~cm}$ Secchi disk. Measurements at capture were assumed to represent an approximation of the recent local environmental conditions experienced by each fish. Due to the rarity of this Critically Endangered fish and the fact that samples were archived across multiple independent surveys, archived specimens were often distributed unevenly in space and time, thus limiting our ability to account for fine-scale variation among years, months, and regions (Table 1; Fig. S1 in Supplement 2). However, specimens were collected across broad regions and gradients in environmental conditions, providing an opportunity to examine how vital rates, such as growth, vary regionally and in relation to the physical environment (Table 1).

\subsection{Otolith preparation}

Otolith preparation and analysis followed standard protocols previously described for delta smelt (Hobbs et al. 2007, 2019). Sagittal otoliths (Fig. 2A) were dissected from fish and stored dry in tissue culture trays or in $95 \%$ ethanol in $1 \mathrm{ml}$ polypropylene tubes. Before mounting, dry otoliths were soaked in $95 \%$ ethanol for up to $24 \mathrm{~h}$, and adherent tissue was removed from all otoliths. Otoliths were then air dried and mounted onto glass slides with Crystal Bond® ${ }^{\circledR}$ thermoplastic resin in the sagittal plane. Each otolith was sanded to the core on both sides with 1200 grit wet-dry sandpaper and polished with $0.3 \mu \mathrm{m}$ alumina on a polishing wheel (MTI). Otoliths were imaged at 200x magnification using a 10 megapixel AM Scope digital microscope camera attached to an Olympus CH30 compound microscope. Multiple images of each otolith were merged into a single composite image using Adobe Photoshop (ver. 21.1.1), and an aging transect was drawn from the core to the dorsal edge at approximately $90^{\circ}$ to the rostral-postrostral axis of the otolith (Fig. 2A,B).

\subsection{Analysis of otolith microstructures}

Daily increments were annotated along the dorsal lobe (core to edge) of each composite otolith image using Image-J 4.0 (United States National Institutes of Health; https://imagej.nih.gov/ij/) (Fig. 2B). The total number of increments represented each specimen's age (in days post hatch, dph), while increment widths, converted from pixels to microns using a stage micrometer, represented the daily otolith growth rate (in $\mu \mathrm{m} \mathrm{d}^{-1}$ ). Prior to analysis, image quality at the dorsal edge of each otolith (Fig. 2C) was scored from 1 to 3 , with 1 being highest quality, and images with the lowest-quality edges (3) were excluded from analysis. Multiple increment profiles were generated for each otolith by 2 or more independent analysts, and the inter-operator precision was evaluated for each sample using the average coefficient of variation (ACV) (Welch et al. 1993, Herbst \& Marsden 2011). If consensus (ACV <10\%) was not achieved for all age readings, the estimate furthest from the mean was discarded and ACV was recalculated until consensus was achieved among a minimum of 2 reads, or the sample was excluded from analysis. ACV was evaluated similarly for edge distance of the last $14 \mathrm{~d}$ of growth. Following the above procedures, the final dataset included otoliths from a total of 459 delta smelt (Table 1; Tables S1-S3).

\subsection{Growth rate}

Recent growth rate was quantified for each specimen using the widths of the last 14 daily increments accreted prior to capture. The $14 \mathrm{~d}$ interval was chosen as a compromise to maximize both the precision of growth estimates and their temporal proximity to 


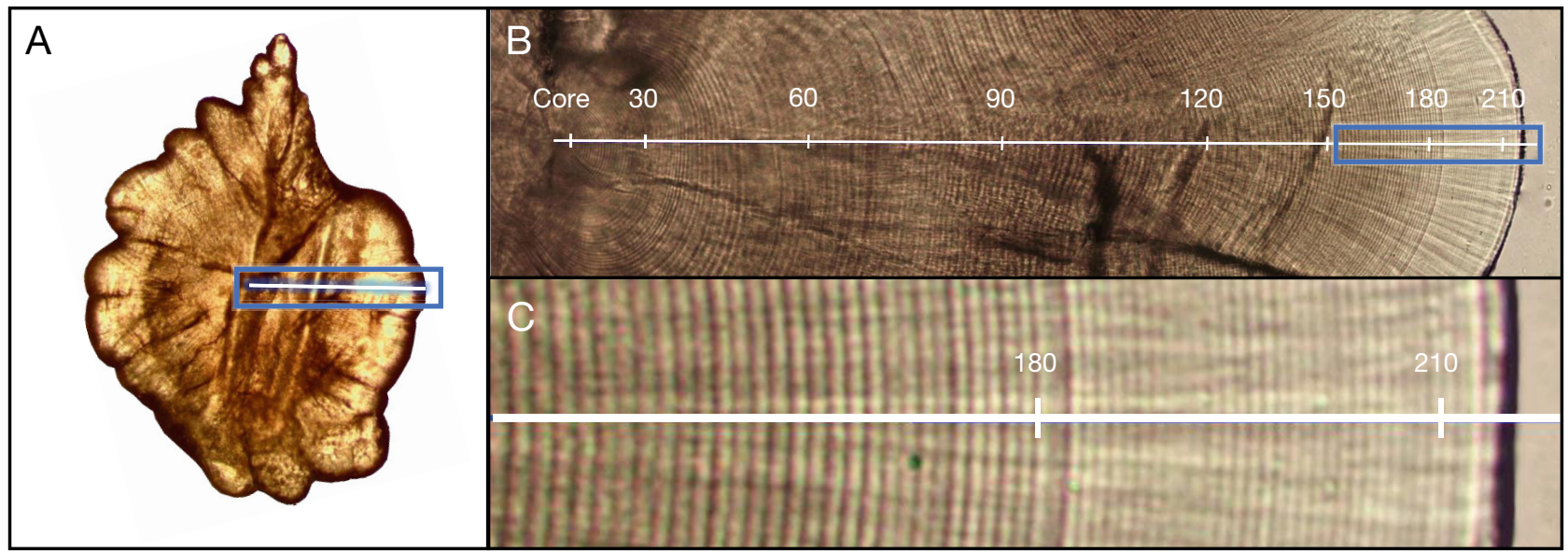

Fig. 2. Otolith of a $215 \mathrm{~d}$ post hatch delta smelt. (A) Whole otolith showing dorsal age trajectory (blue box). (B) Polished dorsal age trajectory (magnification of the blue box in panel A) showing daily rings and last $\sim 60 \mathrm{~d}$ prior to capture (outlined by the blue box). (C) Zoomed-in edge of the polished age trajectory (blue box in panel B) showing the last 20 daily increments prior to collection

environmental measurements (Fig. S2 in Supplement 3) (Baltz et al. 1998). Daily otolith growth rates $\left(\mu \mathrm{m} \mathrm{d}^{-1}\right)$ were converted into somatic growth rates $\left(\mathrm{mm} \mathrm{d}^{-1}\right)$ using the biological intercept model:

$$
L_{a}=L_{c}+\left(O_{a}-O_{c}\right)\left(L_{c}-L_{i}\right)\left(O_{c}-O_{i}\right)^{-1}
$$

where $L_{a}$ is the back-calculated length of the fish at age $a, O_{a}$ is the otolith size at age $a_{1} L_{c}$ and $O_{c}$ are the size (length) of the fish and otolith at capture, respectively, and $L_{i}$ and $O_{i}$ are the size (length) of the fish and otolith at the biological intercept, respectively (Campana 1990, Campana \& Jones 1992, Hobbs et al. 2007). This method assumes consistent proportionality in the otolith-somatic size relationship over the size range of fish examined, which has been confirmed for delta smelt $>10 \mathrm{~mm}$ in recent validation studies (Xieu et al. in press). Recent growth rate $(G)$ of a given fish was calculated as the $\log _{10}$-transformed mean somatic growth rate:

$$
G=\log _{10}\left(\frac{1}{\mathrm{n}} \sum_{i}^{\mathrm{n}} y_{i}\right)
$$

where $y_{i}$ is the somatic growth rate $\left(\mathrm{mm} \mathrm{d}^{-1}\right)$ for day $i$, and $\mathrm{n}$ is the number of days included in the growth interval $(n=14)$. The $\log _{10}$ transformation was used to homogenize the variance across age groups. Adjusted growth rates $\left(G_{a}\right)$ were estimated using the residuals of the intrinsic model (see Section 2.6).

\subsection{Statistical analyses}

We used generalized additive models (GAMs) to quantify how delta smelt growth rates varied in rela- tion to intrinsic and extrinsic factors. GAMs were preferred over linear models because they are more flexible for describing complex non-linear relationships between response and predictor variables (Wood 2017). Intrinsic factors included prior growth and daily age, which accounted for inherent individual and ontogenetic variation in growth rates. Extrinsic factors included region, year, temperature, salinity, and clarity, together representing many of the spatial, temporal, and environmental factors over which growth rates are likely to vary. Water quality attributes were transformed to limit leverage and improve model performance, and correlations among each transformed metric were examined to assess collinearity among predictors. Density plots of water quality attributes were used to identify and exclude outlying values that were too sparse to yield confident predictions.

All GAMs were constructed using a Gaussian distribution, identity link function, thin-plate regression spline, and restricted maximum likelihood (REML) to estimate smooth parameters in the 'mgcv' package (Wood 2017) in R version 3.6.3. Model complexity was limited to a basis dimension of $\mathrm{k}=4$ for main effects or $\mathrm{k}=3$ for interactions to limit over-smoothing and maintain generalizability (Grimaldo et al. 2017). Interactive effects of environmental conditions on growth rates were modeled using tensor product smooths ('ti' in 'mgcv'). Growth responses were examined by plotting partial residual smooths for each of the variables in the model (2-D plots) and their interactions (3-D plots), and model assumptions were assessed using the 'gam.check' and 'concurvity' functions in 'mgcv.' 


\subsubsection{Intrinsic models}

Growth rates were first modeled as individual and combined functions of 2 intrinsic factors, age-at-capture (herein 'age') and prior (larval) growth rate (0$30 \mathrm{dph})$, that often explain significant variation in the growth rates of young fishes (Hinrichsen et al. 2010, Schismenou et al. 2014, 2016). For example, intrinsic models account for the inherent dependence structure of otolith increments with age (ontogenetic effect) and previous growth rates (e.g. individual variation or increment autocorrelation) (Morrongiello \& Thresher 2015, Barrow et al. 2018). Adjusted growth rate $\left(G_{a}\right)$ for each fish was calculated as the residual variation in growth after accounting for the selected intrinsic model (Shima \& Swearer 2019).

\subsubsection{Extrinsic growth models}

Several extrinsic models were constructed to examine how growth rates $\left(G_{a}\right)$ of delta smelt vary as functions of the individual and interactive effects of ambient physical environmental conditions (i.e. water temperature, salinity, and clarity), aggregated regions (West Delta [WD], Central Delta [CD], North Delta [ND], and South Delta [SD], see Table 1) and among years (2011-2019). First, a series of hierarchical 'environment-only' models were constructed, which included temperature, salinity, and clarity as fixed additive and interactive smooth factors, with parameters selected using a maximum likelihood (method = 'ml') estimator. Models were compared using the dredge function from the 'MuMIn' package in R (Barton 2019), with model criteria (estimated degrees of freedom, coefficient of determination $\left[\mathrm{R}^{2}\right]$, and corrected Akaike's information criterion $\left[\mathrm{AIC}_{\mathrm{C}}\right]$ ) used to select the preferred model that was logical, parsimonious, and provided a relatively good fit to the data (Pedersen et al. 2019). These environment-only models were constructed under the simplifying assumption that any variation observed in growth rate was related to variation in the observed physical environmental conditions, independent of other spatiotemporal variation (e.g. years and regions) or environmental conditions (e.g. prey abundance, toxins, etc.) that could influence growth.

Other unmeasured environmental conditions (e.g. prey abundance, etc.), however, may have also varied in time and space and influenced the observed growth patterns. To assess potential spatial variation in growth rates, we constructed a generalized additive mixed effects model, the 'global-regional model,' which included strata that were aggregated into regions as parametric fixed effects, year as a random smooth effect (bs = 're'), as well as the main effects of temperature, salinity, and clarity, each modeled as a fixed smooth effect. By including region as a fixed effect and year as a random effect, we aimed to test for evidence of significant spatial variation in growth while controlling for the main fixed effects of environmental conditions and random interannual variation (Pedersen et al. 2019). Since regions exhibited evidence of different growth responses given global environmental smooths, but also varied greatly in the ranges of each environmental metric (especially salinity, see Section 3), as well as variation in the respective years with available delta smelt specimens, growth rate was also modeled separately for each region as a function of the environmental variables and random effect of year, the 'region-specific models,' thus allowing us to assess region-specific responses in $G_{a}$ to environmental conditions, without assuming global smooth functions or equivalent ranges for each environmental metric (as in previous models).

\section{RESULTS}

\subsection{Intrinsic growth model}

Intrinsic models varied in complexity with 1-7 estimated degrees of freedom (Fig. 3A), explaining $20-60 \%$ of the variation in growth. Age alone $\left(\chi^{2}=\right.$ 442.3, $\mathrm{df}=3.03, \mathrm{p}<0.001)$ explained $>60 \%\left(\mathrm{R}^{2}=0.61\right)$ of the variation in log-transformed delta smelt growth rates $(G)$. Prior growth $\left(\mathrm{R}^{2}=0.18\right)$ and its additive $\left(\mathrm{R}^{2}=\right.$ $0.63)$ and interactive $\left(R^{2}=0.64\right)$ effects with age contributed little to the fit of intrinsic growth models (Fig. 3B), indicating that marginal growth rates were largely independent of early growth history. Although additive and interactive intrinsic models explained 2-3\% more variance than age alone, the complexity (EDF) of these models was considerably higher, resulting in similar AIC values (Fig. 3C); therefore, the age-intrinsic model was selected as the most parsimonious model for describing intrinsic drivers of delta smelt growth rates (Fig. 3D-F). Residuals of this model provided log-transformed growth rates $\left(G_{a}\right)$ which were independent of ontogenetic influences on the mean and distribution of growth values.

\subsection{Environmental attributes}

Archived wild delta smelt specimens used in this study were collected across broad ranges of environ- 

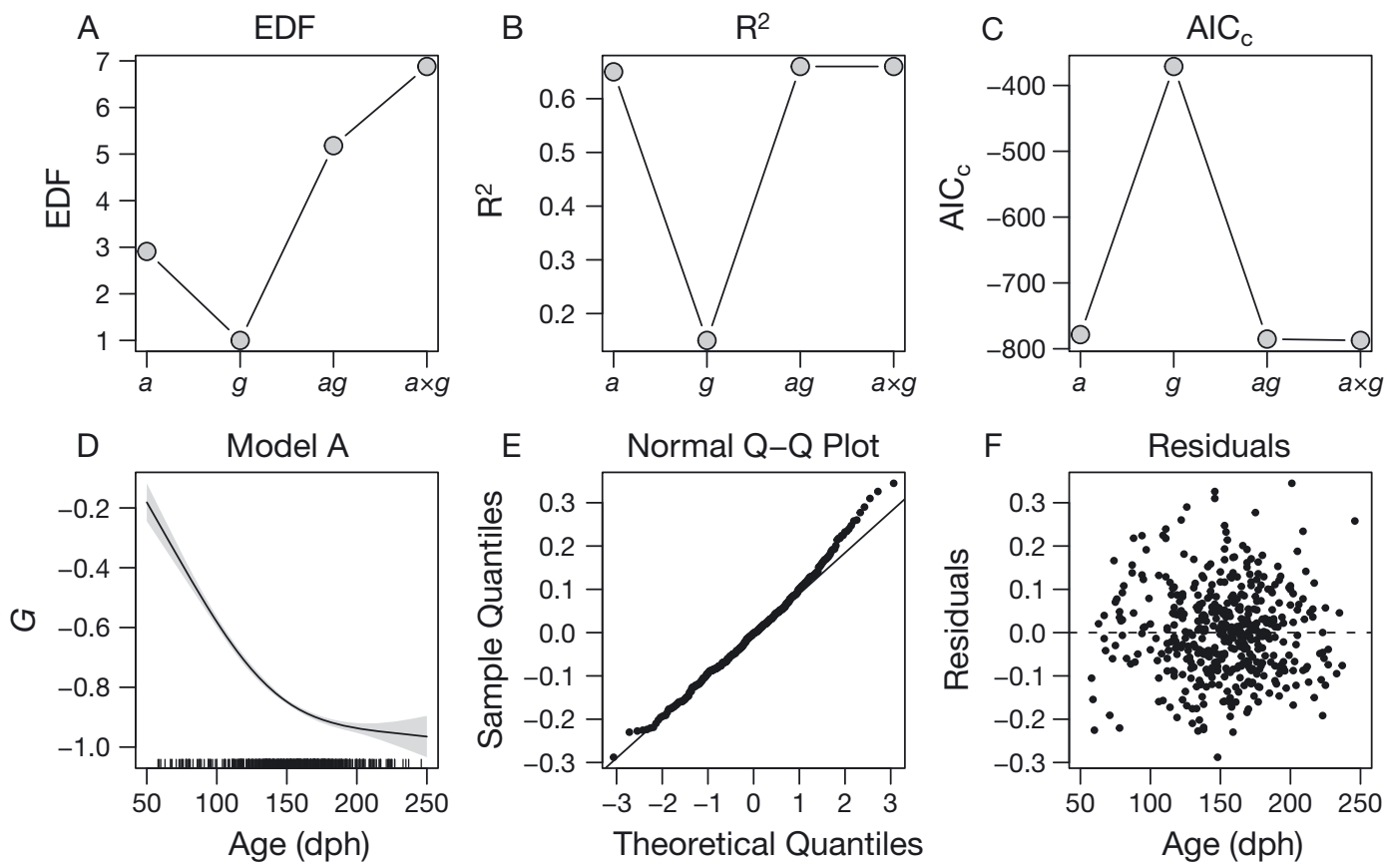

Fig. 3. Intrinsic generalized additive models (GAMs) examining the response of log-transformed recent growth rates $(G)$ to age and prior growth rate. Intrinsic models included age (' $a$ '), prior growth (' $g$ '), and their additive ('ag') and interactive ('ax $g$ ') effects. Models were evaluated by examining (A) complexity (estimated degrees of freedom, EDF), (B) fit (coefficient of determination, $\mathrm{R}^{2}$ ), and $(\mathrm{C})$ quality (corrected Akaike's information criterion, $\mathrm{AIC}_{\mathrm{c}}$ ). (D) The intrinsic relationship between growth rate and age (preferred model, 'A') is shown, along with assessments of (E) normality and (F) homogeneous variance of this model. The centered residuals of the intrinsic model in panel (F) represent the age-independent ('age-adjusted') growth rate $G_{a}$

mental conditions that varied in both space and time (Fig. 4). Water temperatures ranged from 12.5 to 23.9, practical salinity ranged from 0.06 to 6.38 , and clarity ranged from 0.16 to $0.67 \mathrm{~m}$ Secchi depth. Since distributions of temperature and salinity were left- and right-skewed, respectively, each was transformed (temperature: cubic; salinity: log) to improve model performance and reduce leverage of clustered values. Transformed water quality metrics associated with delta smelt collections were largely uncorrelated, thus allowing us to examine the individual and combined effects of each metric (Fig. 4D-F, Table 2).

\subsection{Extrinsic growth models: 'environment-only' model}

Extrinsic abiotic habitat attributes (temperature, salinity, clarity) in the environment-only models explained up to $20 \%$ of the variance in adjusted growth rates (Fig. 5; Fig. S2). Although models including the 3-way interaction resulted in a lower $\mathrm{AIC}_{\mathrm{c}}$ and higher $\mathrm{R}^{2}$, the limited sample size and dispersion across all 3 dimensions, and high ( $>0.9$ ) concurvity for many terms suggested this model was likely over- fit. Therefore, we selected the tsc interactive model with each of the 2-way interactions (tsc ${ }^{*}$, Model 18; see Table S4 in Supplement 3), which was similar in all evaluation criteria to Models 12 and 15 (Fig. S2), yet allowed for visualization of interactive effects on growth for each pair of predictor variables (Fig. 5, Table 3$)$. The $\mathrm{tsc}^{*}$ model explained $16 \%$ of the variance in $G_{a}$ and was significantly different from the null model $\left(\chi^{2}=281.8, \mathrm{df}=14.13, \mathrm{p}<0.001\right.$, Table 3$)$. Overall, $G_{a}$ declined with increasing temperatures above approximately $20^{\circ} \mathrm{C}(\mathrm{p}<0.001$, Fig. $5 \mathrm{D})$, in-

Table 2. Results of correlation analyses among pairs of the abiotic environmental attributes measured with each sample, including their respective transformations: temperature (cubic), salinity $\left(\log _{10}\right)$, and Secchi depth (none). Pearson's correlation coefficient $(\mathrm{r}), t$-statistic $(t)$, degrees of freedom (df), and p-value (p) are provided for each correlation. All pairwise correlations were relatively weak $(|r|=0.04-0.07)$, and none was significant

\begin{tabular}{|lcccc|}
\hline Correlation & $\mathrm{r}$ & $t$ & $\mathrm{df}$ & $\mathrm{p}$ \\
\hline Temperature-Salinity & -0.03 & -0.43 & 159 & 0.665 \\
Temperature-Secchi & -0.07 & -0.85 & 159 & 0.394 \\
Secchi-Salinity & -0.05 & -0.58 & 159 & 0.560 \\
\hline
\end{tabular}



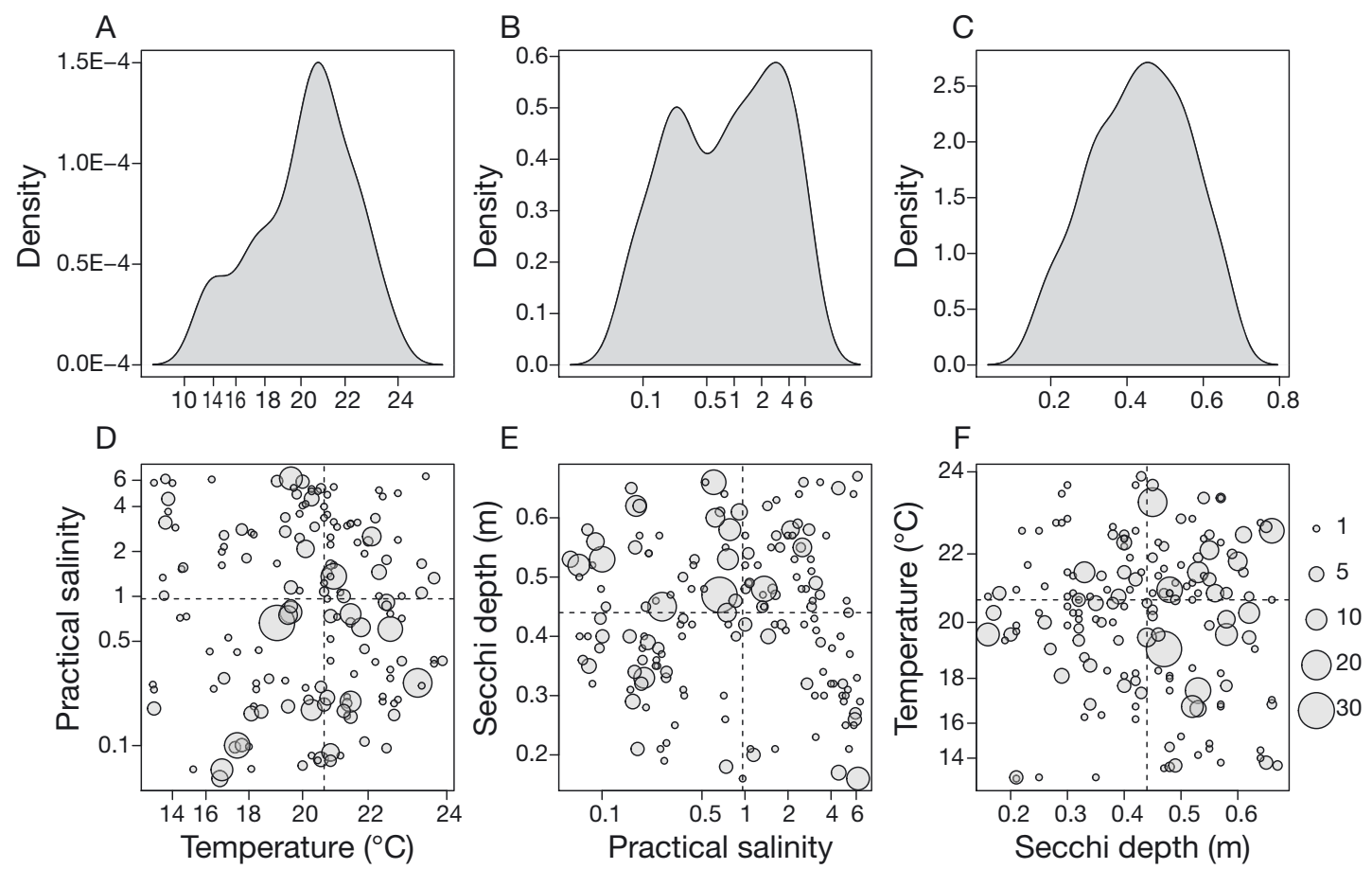

Fig. 4. Distribution of environmental conditions from which delta smelt were collected. Axis scales reflect the respective transformations for temperature (cubic), salinity $\left(\log _{10}\right)$, and Secchi depth (none). Kernel density plots of (A) temperature, (B) salinity, and (C) Secchi depth and (D-F) biplots of each pairwise combination of these metrics, respectively, are shown. Vertical and horizontal lines represent median values. Points reflect individual tows and point size reflects the number of fish associated with a given tow

creased with practical salinity values of $0.1-6(\mathrm{p}=$ 0.007, Fig. 5E), and exhibited a non-significant decreasing trend with water clarity $(\mathrm{p}=0.217$, Fig. 5F, Table 3). A significant temperature-clarity interaction $(p=0.005$, Table 3$)$ indicated that growth rates were highest in turbid-cool, clear-cool, and even turbid-warm conditions, but lowest in clear-warm environments (Fig. 5G). Other interactions were not significant $(p>0.05)$.

\subsection{Extrinsic growth models: 'global-regional' model}

Qualitative exploration of spatial and temporal variation in growth indicated that, overall, growth appeared to vary more within years and regions than among years and regions, but some trends were worth noting (Table 1; Fig. S1). Annual patterns in growth indicated a potential decline in growth rates during warm drought conditions from 2013 to 2016, and recovery following several wet years in $2017-$ 2019. In 2012, growth was generally higher in the western portion of the delta smelt range (i.e. Lower Sacramento River and Suisun Bay-Marsh) than in the North Delta. In Suisun Bay-Marsh and the Lower Sacramento River, growth was higher in 2012 than in 2017. A few fish were collected from the Upper Sacramento River in 2015 (during the warmest drought period), many of which exhibited low growth rates. Conversely, a few fish were collected in the Far Western region in 2011, many of which exhibited high growth rates.

The 'global-regional' model (Fig. 6, Table 4), which accounted for environmental, interannual, and spatial effects, accounted for $30.0 \%$ of the variance in $G_{a}$ $\left(\chi^{2}=168.0, \mathrm{df}=15.4, \mathrm{p}<0.001\right.$, Table 4$)$ and indicated a significant positive effect of salinity on delta smelt growth ( $p=0.049$, Fig. $6 C)$, whereas the effects of temperature, salinity, and region did not contribute significantly to the model ( $p>0.05)$. In contrast, removing the random year term from the model resulted in a model that explained $12 \%$ of the variance in $G_{a}\left(\chi^{2}=59.5, \mathrm{df}=7.2, \mathrm{p}<0.001\right.$, Table 4$)$ and included significant region and temperature effects (Fig. 6E,F). For this model, delta smelt captured in the WD and CD exhibited higher growth rates than those captured in the ND ( $p=0.001$, Fig. 6A) and reduced growth at higher temperatures. The contrasting results of these 2 models (with and without 
A

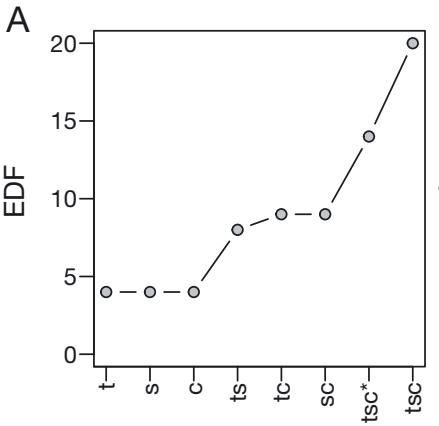

D

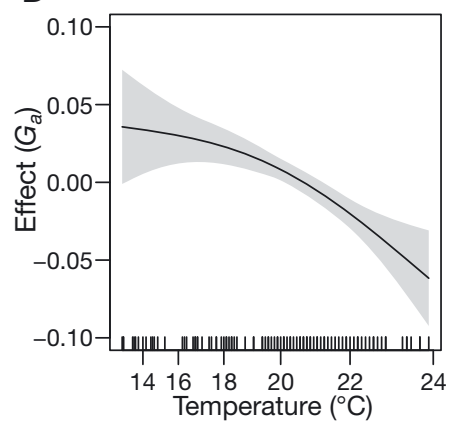

G

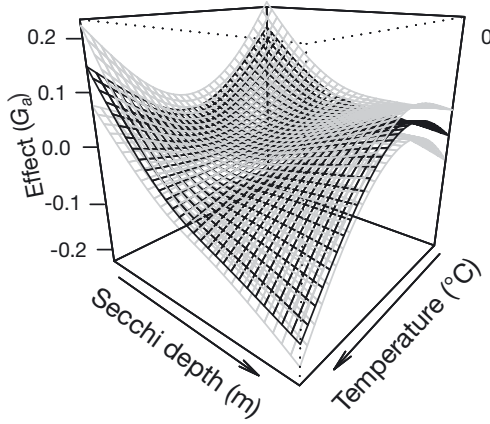

$B$

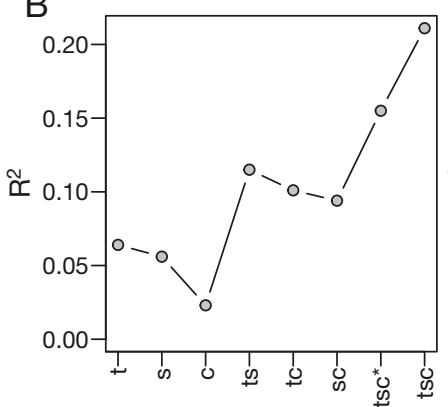

$\mathrm{E}$

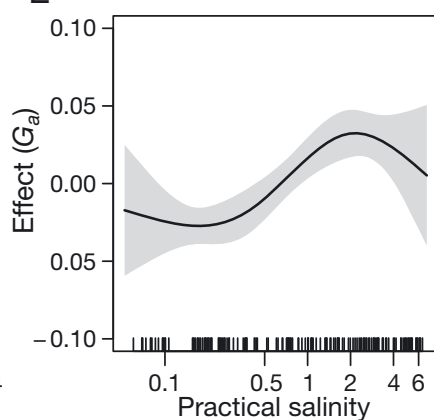

$\mathrm{H}$

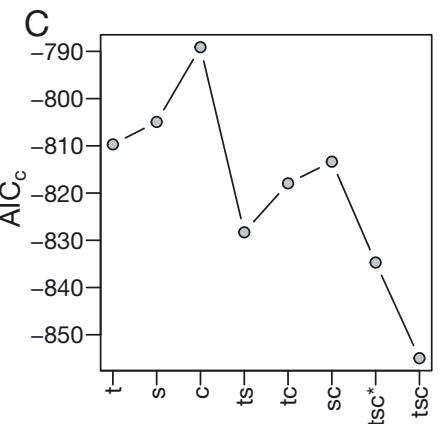

$\mathrm{F}$

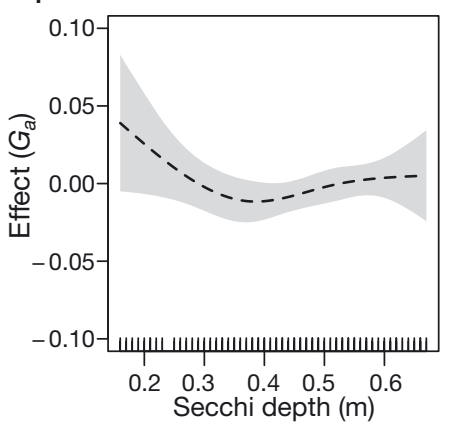

I

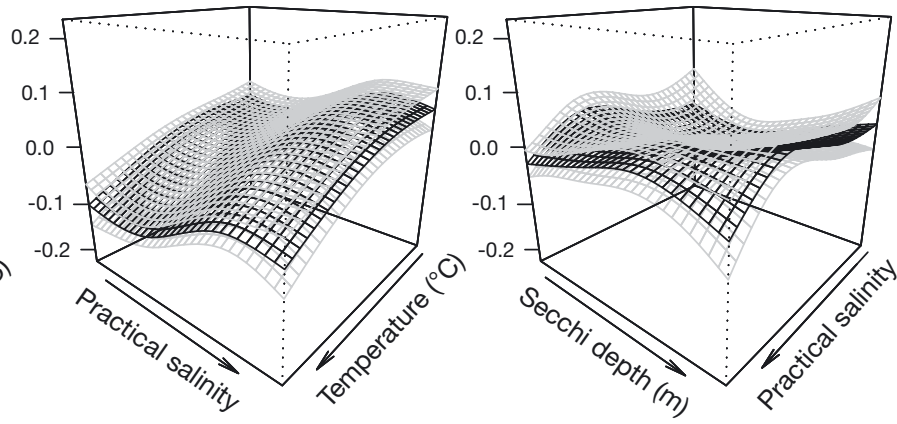

Fig. 5. Results of the 'environment-only' GAM examining variation in age-independent growth rates $\left(G_{a}\right)$ of wild delta smelt as additive and interactive functions of the physical environmental attributes measured at capture. Model selection criteria, including (A) the estimated degrees of freedom (EDF), (B) coefficient of determination $\left(\mathrm{R}^{2}\right)$, and (C) corrected Akaike's information criterion $\left(\mathrm{AIC}_{\mathrm{c}}\right)$ are shown for the univariate and fully interactive 2-way and 3-way subsets of models, along with the selected 2-way model without the 3-way interaction ( $\mathrm{tsc}^{*}$, where $\mathrm{t}$ : temperature, s: salinity, c: clarity). Partial residual smooth plots of the main effects of (D) temperature, (E) salinity, and (F) clarity are shown along with (G-I) the 2-way interactive effects modeled as surfaces using tensor product smooths for the selected tsc ${ }^{*}$ model. Solid smooth lines indicate significant effects $(\mathrm{p}<0.05)$. Light grey polygons $(\mathrm{D}-\mathrm{F})$ and surfaces $(\mathrm{G}-\mathrm{I})$ reflect $95 \%$ Bayesian credible intervals. Note that $x$-axes in D-I are scaled according to respective transformations (Fig. 4). Additional models are described and compared in Table S4 and Fig. S2 in Supplement 3

the random year term) indicated a significant negative effect of temperature that partially co-varied among years, as well as a positive effect of salinity that largely co-varied among regions (Fig. S1).

\subsection{Extrinsic growth models: 'region-specific' models}

As demonstrated previously, $G_{a}$ of delta smelt varied among regions when also incorporating global environmental smooths and random year effects across the full dataset (Fig. 6, Table 4). The subset of years and ranges of environmental conditions corresponding with the sample set, however, also varied among regions (Table 1; Fig. S1). For example, delta smelt were not captured in all regions in all years (Table 1), thus the number of years with specimens for each region were 8,9 , and 5 for ND, CD, and WD, respectively. Furthermore, the ranges of each environmental metric from which delta smelt were captured also varied among regions; most notably prac- 
Table 3. Statistical results of the selected 'environment-only' model (Model 18, tsc ${ }^{*}$ ) examining variation in age-independent growth rates $\left(G_{a}\right)$ of wild delta smelt as the additive and interactive effects of the physical environmental attributes measured at capture (temperature, salinity, and clarity) $\left(\chi^{2}=\right.$ 79.6, $\left.\mathrm{df}=15.6, \mathrm{R}^{2}=0.159, \mathrm{p}<0.001\right)$. Estimated degrees of freedom $(\mathrm{EDF})$, referenced degrees of freedom (RDF), Fratio, and p-values are provided for each term in the model. Significant $p$-values $(p<0.05)$ for each coefficient and smooth term are in bold. Additional models are described and compared in Table S4 and Fig. S2 in Supplement 3

\begin{tabular}{|lccrc|}
\hline Factor & EDF & RDF & $F$ & $p$ \\
\hline Temperature & 1.86 & 2.24 & 10.46 & $<\mathbf{0 . 0 0 1}$ \\
Salinity & 2.60 & 2.86 & 5.35 & $<\mathbf{0 . 0 0 1}$ \\
Clarity & 2.29 & 2.63 & 1.79 & 0.217 \\
Temperature×Clarity & 1.92 & 1.99 & 5.68 & $\mathbf{0 . 0 0 5}$ \\
Temperature×Salinity & 1.00 & 1.00 & 0.04 & 0.844 \\
Clarity $\times$ Salinity & 2.60 & 3.21 & 1.29 & 0.312 \\
\hline
\end{tabular}

tical salinity, where delta smelt from the ND were mostly captured in waters at values $<0.5$ and the $C D$ at values $<4$, whereas fish from the WD were captured in the full range of salinities in the dataset, from values of 0.1 to 6.4 (Fig. S1G). Temperatures were generally warmer for fishes captured in the ND and clarity was generally higher in the CD; however, the ranges of these metrics exhibited more overlap among regions than salinity (Fig. S1F,H).

Due to the potential effects of this region-specific variation, we fit separate region-specific GAMs that examined $G_{a}$ as a function of the additive smooth effects of the physical environmental attributes (temperature, salinity, and clarity), and the random effect of year (2011-2019), thus allowing us to assess regionspecific and year-independent responses of $G_{a}$ to environmental variation without assuming global smooth functions or similar ranges for each environmental attribute across regions. Models for all 3 regions were significantly different from the null $(\mathrm{p}<$ 0.001 ) and accounted for $20-45 \%$ of the variance in growth $\left(G_{a}\right)$ (Fig. S4 and Table S5 in Supplement 5). In the $C D, G_{a}$ declined significantly at temperatures above $20^{\circ} \mathrm{C}$ (Fig. S4D) and increased linearly with increasing salinity values from 0.1 to 6 (Fig. S4E), while exhibiting no significant effects of clarity (Fig. S4C). In contrast to the CD, the ND and WD exhibited only significant interannual variation in growth, with no significant effects of the environmental metrics (Fig. S4A-C).

\section{DISCUSSION}

Growth is a key vital rate of fishes that serves as an integrated proxy for the effects of environmental variation on individual fitness and subsequent population dynamics (Hjort 1914, Houde 1989, 2008, Rose et al. 2013a). Here, we utilized an archive of wild
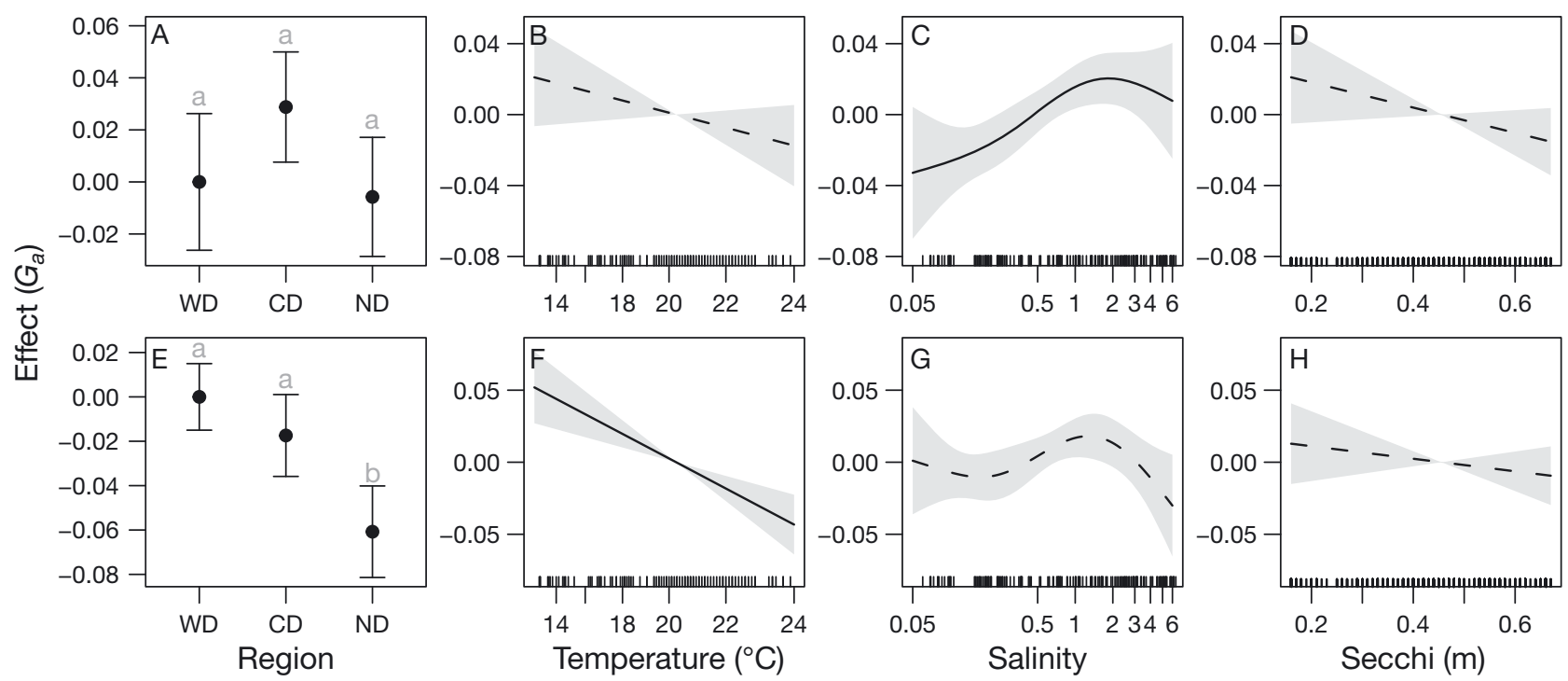

Fig. 6. Results of the 'global-regional' GAMs examining variation in age-independent growth rates $\left(G_{a}\right)$ as a function of the fixed parametric effect of (A) region, and the additive smooth effects of (B) temperature, (C) salinity, and (D) clarity, while including a random year effect. (E-H) Results of the same models, respectively, when excluding the random year term. Regional effects $(A, E)$ are represented by the parametric coefficients $\pm S E$, with letters indicating significant differences among regions $(p<0.05)$. Significant smooth effects are indicated by solid lines $(\mathrm{p}<0.05)$, with shading indicating the $95 \%$ Bayesian credible intervals. Region abbreviations are as in Table 1. By including the random effect of year (A-D), variance associated with temperature was assigned to the year effect, and variance associated with regional differences was assigned to the year and salinity effects 
Table 4. Statistical results of the 'global-regional' generalized additive model (GAM) examining variation in age-independent growth rates $\left(G_{a}\right)$ as a function of the fixed parametric effect of region, and the additive smooth effects of temperature, salinity, and clarity, both with and without the random effect of year (Model). The estimated coefficients (coefficient), standard error of the estimate (SE), $t$-statistic $(t)$, and $\mathrm{p}$-value $(\mathrm{p} 1)$ are provided for each parametric term. Estimated degrees of freedom (EDF), referenced degrees of freedom $(\mathrm{RDF}), F$-ratio $(\mathrm{F})$, and p-values (p1) are provided for each smooth term in the model. The overall $\mathrm{R}^{2}$ and $\mathrm{p}$-value (p2) of each model are also provided. Significant $p$-values $(p<0.05)$ are shown in bold. WD: West Delta; CD: Central Delta; ND: North Delta

\begin{tabular}{|c|c|c|c|c|c|c|}
\hline Model: + Year & & & & & $\mathrm{R}^{2}$ & p2 \\
\hline$\underline{\text { Parametric Terms }}$ & Coefficient & $\underline{\mathrm{SE}}$ & $\underline{t}$ & p1 & 0.3 & $<0.001$ \\
\hline Intercept (WD) & -0.031 & $0 . \overline{026}$ & -1.170 & 0.243 & & \\
\hline $\mathrm{CD}$ & 0.029 & 0.021 & 1.359 & 0.175 & & \\
\hline ND & -0.006 & 0.023 & -0.251 & 0.802 & & \\
\hline$\underline{\text { Smooth Terms }}$ & $\underline{E D F}$ & $\underline{\mathrm{RDF}}$ & $\underline{F}$ & $\mathrm{p} 1$ & & \\
\hline Temperature & $\frac{.000}{1.000}$ & $\frac{\underline{1.00}}{1.000}$ & 2.331 & 0.128 & & \\
\hline Salinity & 2.226 & 2.593 & 3.896 & 0.028 & & \\
\hline Secchi & 1.001 & 1.001 & 2.590 & 0.108 & & \\
\hline Year & 7.014 & 8.000 & 14.273 & $<0.001$ & & \\
\hline Model: - Year & & & & & $\mathrm{R}^{2}$ & $\mathrm{p} 2$ \\
\hline$\underline{\text { Parametric Terms }}$ & $\underline{\text { Coefficient }}$ & $\underline{\mathrm{SE}}$ & $\underline{t}$ & p1 & 0.12 & $<0.001$ \\
\hline Intercept (WD) & 0.024 & 0.015 & 1.623 & 0.105 & & \\
\hline $\mathrm{CD}$ & -0.017 & 0.018 & -0.943 & 0.346 & & \\
\hline ND & -0.061 & 0.021 & -2.947 & 0.003 & & \\
\hline$\underline{\text { Smooth Terms }}$ & $\underline{E D F}$ & $\underline{\mathrm{RDF}}$ & $\underline{F}$ & $\mathrm{p} 1$ & & \\
\hline Temperature & 1.002 & 1.004 & 17.382 & $<0.001$ & & \\
\hline Salinity & 2.576 & 2.863 & 2.026 & 0.084 & & \\
\hline Secchi & 1.000 & 1.000 & 0.845 & 0.358 & & \\
\hline
\end{tabular}

delta smelt otoliths to assess how growth rates of this Critically Endangered fish vary ontogenetically and in relation to in situ environmental conditions experienced at capture. The environment-only model indicated that temperature, salinity, and clarity each explained a significant fraction of the age-independent variation in growth rates. Growth rate rapidly declined by $19 \%$ as temperatures increased from 16 to $23^{\circ} \mathrm{C}$, increased by $16 \%$ as salinity increased from 0.1 to 4.0 , and exhibited a complex temperaturedependent response to clarity, with cool-turbid water corresponding with $38 \%$ faster growth relative to warm-clear habitats (e.g. $16^{\circ} \mathrm{C}$ and $0.2 \mathrm{~m}$ Secchi depth vs. $23^{\circ} \mathrm{C}$ and $0.7 \mathrm{~m}$ Secchi depth, respectively). Results of the spatially explicit global model (without year) indicated that growth rates were $13 \%$ higher in the WD versus the ND, while region-specific models indicated distinct patterns among regions in growthenvironment relationships.

Despite this complexity, these results strongly indicate that the negative physiological responses of wild delta smelt to continued warming may be even more severe than previously described (Feyrer et al. 2007, Nobriga et al. 2008, Komoroske et al. 2014, 2015, Brown et al. 2016, Jeffries et al. 2016), and that concurrent increases in water clarity throughout the Delta (Hestir et al. 2016, Bever et al. 2018) are likely to further exacerbate the effects of warming on the wild population. With delta smelt on the brink of extinction, managers are seeking science-based guidance regarding effective management options to conserve this species (Hobbs et al. 2017, Moyle et al. 2018). Several options have gained traction, including indirect food-web augmentation via wetland restoration and flow modification, direct population augmentation via the release of cultured fish into the species' existing habitat, and transplanting delta smelt into new, more environmentally hospitable habitats. Our results indicate that as habitats within the existing range of this species continue to warm and clarify, they will become increasingly inhospitable for delta smelt; thus, any long-term solution likely needs to address these impending changes.

\subsection{Intrinsic effects}

We first assessed and controlled for a dominant intrinsic ontogenetic pattern in growth rate, which is a critical initial step in assessing variation in daily growth rates of young fishes (Weisberg et al. 2010, Morrongiello \& Thresher 2015, Barrow et al. 2018, Shima \& Swearer 2019). Using a 2-step modeling approach (Morrongiello \& Thresher 2015, Shima \& Swearer 2019), we were able to partition the variance between intrinsic ontogenetic and extrinsic abiotic environmental and regional factors to assess relationships between environmental conditions and age-independent growth rates of wild delta smelt. Approximately $60 \%$ of the variation in growth rates was explained by age, alone, with growth rates ranging from 0.1 to $0.6 \mathrm{~mm} \mathrm{~d}^{-1}$, decreasing rapidly with daily age from 50 to $200 \mathrm{dph}$. Inclusion of prior growth rates did not improve the intrinsic growth models, suggesting that the age-specific pattern in growth was largely independent of an individual's prior growth history. Although age-specific growth 
rates are often correlated with the prior growth history of an individual (e.g. for inherently fast- and slow-growing fish), variation in daily growth can exhibit little correlation with prior growth if separated by longer time intervals (Hinrichsen et al. 2010, Schismenou et al. 2014, 2016), possibly explaining why the $14 \mathrm{~d}$ recent growth interval did not exhibit autocorrelation with prior larval growth.

\subsection{Extrinsic effects: temperature}

Otolith-based reconstructions of growth rates for wild delta smelt indicated that growth declined rapidly as temperatures increased to over $20^{\circ} \mathrm{C}$ (Fig. 5D), especially in the Lower Sacramento River (Fig. S4D). In ectothermic fishes, growth rate is typically strongly and positively correlated with water temperature due to the kinetic effects of temperature on metabolism. Both growth and metabolism increase with temperature until a maximum growth rate is reached, after which growth rate is suppressed due to thermal stress or metabolic imbalance between energy expense and consumption (Brett \& Groves 1979, Pörtner \& Peck 2010, Schismenou et al. 2016).

We did not observe a positive response in growth as temperature increased from 13 to $20^{\circ} \mathrm{C}$. Instead, growth rate remained relatively high and stable up until approximately $20^{\circ} \mathrm{C}$, after which growth declined rapidly with increasing temperature. These results suggest that wild adult delta smelt may grow best in cooler waters and exhibit suppressed growth at temperatures above $20^{\circ} \mathrm{C}$, either due to physiological limits or other interacting environmental conditions. This observed decline in growth may indicate that wild delta smelt are chronically stressed throughout much of the upper SFE during the warmest summer-fall conditions, especially in the Lower Sacramento River. For example, rapid warming of the upper SFE during the 2014-2015 drought likely reduced growth rates and survival, and shortened the maturation window of delta smelt, possibly explaining the low abundances observed during these warmer years.

Delta smelt have been captured in trawl surveys at temperatures as high as $27^{\circ} \mathrm{C}$ in the summer, but most subadult fish are observed at temperatures below $22-24^{\circ} \mathrm{C}$ (Bennett 2005, Komoroske et al. 2014). Such catch data, combined with environmental covariates, have been used to describe habitat suitability for delta smelt, suggesting that temperatures below $24-25^{\circ} \mathrm{C}$ are generally suitable (Feyrer et al. 2007). However, Nobriga et al. (2008) indicated that temperature during summer was the poorest predictor of the distribution of delta smelt in the wild, although this was due in part to the limited, high temperature ranges (mostly $>20^{\circ} \mathrm{C}$ ) observed in July and a likely non-linear decline in predicted capture probabilities at approximately $25^{\circ} \mathrm{C}$ that was not captured well by the model. Though informative, such habitat suitability models based on occupancy may not reflect the population-level effects of exposure to specific environmental conditions (Neubauer \& Andersen 2020). For example, the presence of fish in waters with temperatures above $25^{\circ} \mathrm{C}$ does not indicate that conditions are favorable, as it is possible that such fish were trapped in unsuitable conditions that negatively impacted their growth, survival, and future reproductive output. Physiological impairment could decrease swimming activity or net avoidance, thus making fish easier to capture in more stressful conditions. High catches in suboptimal conditions, therefore, could obscure important patterns in physiological condition. Therefore, additional studies are needed to describe the physiological limits most likely to influence population dynamics.

Laboratory studies using cultured fish have examined a variety of behavioral and metabolic responses to acute lethal and sublethal levels of thermal stress. Such experiments have demonstrated a critical thermal maximum $\left(\mathrm{CT}_{\max }\right)$ of $25-30^{\circ} \mathrm{C}$ for cultured delta smelt (Swanson et al. 2000, Komoroske et al. 2014). In contrast, sublethal responses in behavior and gene expression have been consistently observed at temperatures of $23-25^{\circ} \mathrm{C}$ (Komoroske et al. 2015, Jeffries et al. 2016, 2018). The results of these laboratory studies corroborated prior field occupancy models, each suggesting that physiological limits constrain optimal delta smelt habitat to $<25^{\circ} \mathrm{C}$ in the wild (Feyrer et al. 2007, Nobriga et al. 2008), with adults being more sensitive than juvenile life stages (Komoroske et al. 2014). As observed in field studies (Bennett 2005), nearly all delta smelt included in our study were observed at $<22^{\circ} \mathrm{C}$, which is slightly cooler than the sublethal thresholds $\left(23-25^{\circ} \mathrm{C}\right)$ identified in laboratory experiments using cultured fish.

Though growth rates began to decline at temperatures below $20^{\circ} \mathrm{C}$ in the environment-only model (Fig. 5D), fish captured in waters $>22^{\circ} \mathrm{C}$ exhibited the greatest reductions in growth, and the thermal inflection in the $\mathrm{CD}$ region-specific model suggested a slightly higher threshold (e.g. $21^{\circ} \mathrm{C}$, Fig. S4D). Few laboratory studies have examined physiological thermal thresholds below $20^{\circ} \mathrm{C}$, but an increase in susceptibility to disease (caused by Ichthyophthirius multifiliis) in the laboratory was observed at $18^{\circ} \mathrm{C}$ 
relative to fish reared at $16^{\circ} \mathrm{C}$ (Frank et al. 2017), and growth rates of cultured fish were highest at $20^{\circ} \mathrm{C}$, with lower growth rates at both lower $\left(17^{\circ} \mathrm{C}\right)$ and higher $\left(23^{\circ} \mathrm{C}\right)$ temperatures (B. Baskerville-Bridges unpubl. data). These results suggest that a lower thermal threshold for growth may be linked to mechanisms other than commonly measured physiological traits. In sum, our results using otolith-based growth rates of wild fish corroborate previous laboratory and field occupancy studies, each indicating that delta smelt commonly experience stressful thermal conditions in situ that are likely to impact fitness and population dynamics. Our results also suggest that growth rates of wild delta smelt may be suppressed at temperatures below commonly used thresholds established using field occupancy models and physiology experiments with cultured specimens.

\subsection{Extrinsic effects: salinity}

Delta smelt are euryhaline, and thus can tolerate short-term exposures to the full range of salinities from 0 to $32 \mathrm{ppt}$, and exhibit little evidence of physiological stress at practical salinity values $<15$ (Swanson et al. 2000, Nobriga et al. 2008, Hasenbein et al. 2013, Komoroske et al. 2016, Hammock et al. 2017). At practical salinities $>15$, however, delta smelt exhibit significant molecular and physiological impairment, suggesting that prolonged exposure at higher salinities would be energetically detrimental, likely leading to reduced growth rates and other measures of fitness (Hasenbein et al. 2013, Komoroske et al. 2016). This likely limits the range of delta smelt to lower salinities of the upper estuary. In the wild, however, relatively few fish are ever observed at practical salinities $>6$, suggesting that delta smelt avoid even lower salinities than those predicted by laboratory studies examining physiological responses to salinity (Kimmerer 2002, Bennett 2005, Komoroske et al. 2016).

In our study, all specimens were captured at practical salinities of 0.1-6.5 (Fig. S1). This range lies well within the 'suitable' range for delta smelt described above. Growth rates in the environment-only model exhibited a positive, significant relationship with salinity (Fig. 5D). This result corroborated prior studies indicating that foraging success in downstream low-salinity brackish habitats is higher than in upstream freshwater habitats (Hammock et al. 2017). Together, these results indicate that enhanced foraging by delta smelt in low-salinity brackish habitats also confers a measurable and significant increase in individual growth rates. This joint variation in feeding and growth may therefore be a mechanism selecting for the downstream migration of many juvenile-subadult delta smelt from fresh to lowsalinity brackish habitats (Hammock et al. 2017, Hobbs et al. 2019). Similarly, by including region as a parametric fixed term in the global-regional model, results indicated that growth was highest in the WD and $\mathrm{CD}$ and lowest in the ND (Fig. 6A), also suggesting that growth rates of delta smelt are maximized further downstream, where higher foraging success is correlated with low-salinity brackish habitats (Hammock et al. 2017, 2019). Since salinity varied strongly with region (Fig. S1), however, a significant salinity effect was not detected in the global-regional model.

In contrast to the positive salinity-growth relationship in the environment-only model, region-specific models indicated different salinity effects (Fig. S4, Table S5 in Supplement 5). In the ND, growth rates were generally low, and practical salinity values only varied from 0.1 to 0.5 , thus no region-specific effects of salinity were observed (Fig. S4A). In addition to higher foraging success downstream, there is also evidence that higher exposure to contaminants in upstream habitats may also result in poorer fitness (Hammock et al. 2015). In the CD, where most fish were sampled, growth rate exhibited similar patterns as the environment-only model, increasing with practical salinity values of 0.1 to 4 (Fig. S4B). In the WD, however, where salinity was highest and most variable, growth rates did not vary significantly with environmental conditions (Fig. S4C), possibly due to the lower sample size and the presence of most fish in downstream habitats only in high-flow years (year effect). It is also possible that finer-scale interactions with other habitat features (e.g. tidal marshes) that influence foraging and growth (Hammock et al. 2019) could complicate such analyses. Future observational and experimental studies examining differences in growth rates among habitat types within the WD are needed to shed further light on such habitat-environment interactions.

\subsection{Extrinsic effects: clarity}

Turbid conditions can enhance growth and survival of fishes by reducing predation risk and enhancing foraging success (Moore \& Moore 1976, Rypel et al. 2007). In the wild, delta smelt occurrence is positively correlated with higher turbidity (Feyrer et al. 2007, 2011, Nobriga et al. 2008), and in labora- 
tory studies of larval delta smelt, foraging activity and success are maximized in low-light or highly turbid (e.g. 18-80 NTU) conditions (Lindberg et al. 2013, Komoroske et al. 2016, Tigan et al. 2020). Turbidity per se may have less of an effect on foraging by adult delta smelt, and at very high turbidities (e.g. 125-250 NTU), foraging success may be reduced for adult delta smelt (Hasenbein et al. 2013). The nonsignificant main effect of water clarity in the environment-only, global-regional, and region-specific model appears to support this previous result.

Growth rates of wild delta smelt, however, appeared to respond to a significant interactive effect of water clarity and temperature, with individuals exhibiting stable growth rates when captured in more turbid conditions (e.g. Secchi depths $<0.2 \mathrm{~m}$ ), even when water temperatures were high (Fig. 5F,G). In contrast, wild delta smelt exhibited the strongest decline in growth rate with increasing temperature when also observed in clearer waters with higher Secchi depth values. This significant temperature-clarity interaction suggests that enhanced foraging or reduced energetic costs (e.g. due to reduced predation risk or higher prey availability) in turbid conditions may help facilitate growth compensation during periods of thermal stress, as has been shown for other temperate fishes (Lusardi et al. 2020). If so, this may explain, in part, the ability of some freshwater resident delta smelt to survive otherwise thermally stressful conditions during warm summer conditions (Hobbs et al. 2019, Mahardja et al. 2019).

\subsection{Statistical considerations}

Catches of this Critically Endangered species are rare and patchy in the wild; thus, samples were often unbalanced in time, space, and in relation to environmental variation. For this reason, we constructed multiple models to examine specific patterns in the data given varying assumptions. Since delta smelt are not known to school, individuals were assumed to have been dispersed within regions with similar environmental conditions for the last $14 \mathrm{~d}$ prior to capture and were thus treated as independent to maximize the information provided by each fish. It is possible, however, that individual fish experienced different recent environmental histories, thus limiting the relevance of the measured environmental data to each individual; or to the contrary, that towspecific variation may have resulted in a lack of independence among individuals for reasons other than similarity in environmental histories. Next, samples were distributed unevenly among years, subregions, regions, and environmental conditions. For example, most specimens were from just 3 subregions including the Lower Sacramento River, Suisun Bay and Marsh, and the Cache Slough and Liberty Island complex. Therefore, smaller strata were aggregated up into regions, possibly obscuring finer-scale subregional patterns (e.g. Suisun Marsh versus Suisun Bay). Furthermore, most delta smelt captured furthest downstream in the WD region were primarily collected following the wettest years (e.g. 2011-2012, 2017) with higher freshwater outflows that disperse fish and low-salinity habitats further downstream. Similarly, salinity was spatially structured, with specimens from the ND having only experienced freshwater conditions, whereas specimens from the Lower Sacramento River experienced both fresh and low salinity values, and specimens from the WD experienced an even broader range of salinity values.

Our modeling approach included (1) an environmental-only model, (2) a global-regional mixed effects model, and (3) separate region-specific mixed effects models, allowing us to examine how inferences regarding growth responses to environmental and spatiotemporal variation might change given different modeling assumptions. Though hierarchical factor-smooth models can be informative for these types of questions (Pedersen et al. 2019), we chose this modeling approach as the most conservative way to account for the nuances described above. Environment-only models assumed that environmental drivers, alone, explained the variation observed in growth rates, while ignoring temporal and spatial structure in the data. In contrast, the global-regional model assumed that all environmental smooths were identical among regions, and that only the intercepts were affected by region and the global random effect of year. Region-specific models accounted for interannual variation and had the fewest assumptions, but also the smallest sample sizes and lowest power to estimate environmental and interannual effects. The use of multiple models allowed us to examine how growth varies in relation to the environmental attributes when accounting for different structures in the data, thus providing additional confidence in consistent patterns that emerge, while suggesting caution in the interpretation of results that appear less stable. We believe, therefore, that the conclusions reported herein are robust, yet we also emphasize the importance of expanding upon this study, where feasible, to enhance statistical power and to better partition fine-scale spatiotemporal and environmental patterns in delta smelt growth rates. 


\subsection{Management implications}

Conservation efforts for delta smelt currently focus on managing freshwater flows to maintain suitable low-salinity habitats further downstream during summer-fall. During this period, juvenile and subadult delta smelt often occur in low-salinity habitats (e.g. salinities of 0.1-4 ppt) of the upper SFE (Moyle et al. 1992), and it is during this period that variation in vital rates, such as growth, are likely to have strong effects on future reproductive output and subsequent population growth rates (Rose et al. 2013b). Prior studies suggest that higher freshwater flows into the estuary during summer-fall could significantly improve the quantity and quality of low-salinity habitats for delta smelt by improving the abiotic environment (Feyrer et al. 2007, 2011) and increasing food availability (Miller et al. 2012). For example, the highest-quality summer-fall habitats for delta smelt are believed to occur near the $2 \mathrm{ppt}$ isohaline ('X2'), with both the quantity and quality of low-salinity habitats further enhanced when X2 is further downstream (e.g. < river kilometer 81) toward Suisun BayMarsh (Moyle et al. 1992, Jassby et al. 1995, Kimmerer 2002, Dege \& Brown 2004). Field studies linking the vital rates of wild delta smelt to dynamic and static habitat features are needed to explore these hypotheses and the mechanisms likely to confer the theorized benefits of specific freshwater flow management actions.

The patterns in otolith-based growth rates of delta smelt described herein shed additional light on the responses of this species to environmental and geographic habitat attributes, thus improving inferences regarding likely responses to different management actions. Environment-only models indicated that delta smelt grow faster in low-salinity brackish versus freshwater habitats, corroborating previous observations of enhanced foraging by individuals captured further downstream (Hammock et al. 2017). Global-regional models indicated that geographic patterns matched the above predictions, with delta smelt growing slowest in upstream freshwater habitats of the ND, and fastest in the saltier downstream habitats of the $C D$ and WD. While growth rates increased with practical salinity in the $C D$, this pattern was not evident in the WD region-specific model, possibly due to its lower sample size. In aggregate, these results confirm that improved feeding and growth in downstream low-salinity habitats are likely key mechanisms selecting for a migratory life history in delta smelt (Hammock et al. 2017, Hobbs et al. 2019). Our results suggest that water manage- ment actions designed to enhance downstream dispersal and the extent and quality of low-salinity habitats in the summer-fall are likely to benefit delta smelt.

We did not identify clear evidence for a unique effect of salinity on growth rates between the $\mathrm{CD}$ and $\mathrm{WD}$; therefore, our results do not provide clear evidence for or against a specific value of X2 (e.g. relative to river $\mathrm{km} \mathrm{81)} \mathrm{that} \mathrm{maximizes} \mathrm{delta} \mathrm{smelt}$ growth. Nevertheless, our results further indicate that reductions in freshwater outflow due to droughts and diversions, especially combined with rising sea levels, increasing transparency, and continued warming due to climate change, are likely to exacerbate eastward intrusion of more saline waters, which is likely to further compress and degrade the remaining limited low-salinity habitats of delta smelt (Feyrer et al. 2011, Hasenbein et al. 2013, Brown et al. 2016, Komoroske et al. 2016). Specifically, our results suggest that such changes in the upper SFE are likely to negatively impact growth rates of delta smelt, which will likely correspond with reduced fitness and net reproductive output (Hjort 1914, Houde 1989, Cushing 1990, Leggett \& Deblois 1994, Rose et al. 2013b). Therefore, flow management actions that are designed to increase the extent of suitable lowsalinity habitats (Kimmerer et al. 2009) and enhance downstream transport to higher-quality habitats are likely to benefit wild delta smelt. Several hypotheses regarding the benefits of such flow actions focus on associated increases in the intersection of dynamic low-salinity conditions with fixed geographic habitat features such as wetlands and marshes that occur further downstream (e.g. Suisun Marsh). Future otolith-based studies that examine the growth rates of fish captured across these different fixed geographic features, while also controlling for intrinsic growth effects and dynamic environmental attributes such as salinity, could shed further light on the potential benefits of brackish wetland habitats and associated flow management actions for this species.

We are still discovering new facets of the basic biology of delta smelt that have yet to be accounted for in life-cycle and population models, conservation efforts, and the captive breeding program (Hobbs et al. 2019). The presence of multiple life-history phenotypes including freshwater residents (FWRs) suggests that year-round residence of delta smelt in freshwater habitats is likely an important mechanism for population resilience and stability (Nobriga et al. 2008, Hobbs et al. 2019). However, our findings support previous studies suggesting that freshwater habitats are becoming increasingly unsuitable in 
summer-fall due to multiple factors, including thermal stress (Nobriga et al. 2008, Moyle et al. 2016, Hobbs et al. 2019). The likely loss of this life-history phenotype in the SD and its continuing decline in the ND may greatly reduce population resilience, pushing delta smelt ever closer toward extinction. This is especially true if growth is suppressed at temperatures above $20^{\circ} \mathrm{C}$, and further still if this effect is exacerbated in clearer waters, as indicated in this study. FWR delta smelt may, however, compensate for reduced growth rates by avoiding the energetic costs and mortality risk associated with migrating upstream to freshwater spawning grounds. Furthermore, since FWR delta smelt live adjacent to optimal spawning habitats and mature earlier (Hobbs et al. 2019), they may also compensate for reduced growth and size-at-spawning by producing a greater number of broods per spawning season (Damon et al. 2016). Comparative studies of the reproductive biology of different life-history phenotypes would shed further light on their relative fitness and per capita contributions to delta smelt population dynamics.

\subsection{Conclusions}

Our results examining the vital rates of wild delta smelt corroborate and emphasize prior work using cultured fish and occupancy models, all of which indicate that future increases in temperature are likely to negatively impact delta smelt physiology and growth (Nobriga et al. 2008, Komoroske et al. 2014, Brown et al. 2016). Our results also corroborate studies indicating that increasing water clarity (Hestir et al. 2016, Bever et al. 2018) and landward intrusion of higher-salinity waters (Brown et al. 2016, Komoroske et al. 2016, Moyle et al. 2016) are likely to exacerbate the negative effects of future warming on delta smelt. For example, our models indicate strong, interacting effects of environmental conditions on the growth of wild delta smelt, with up to a $38 \%$ decline when conditions are both warm and clear. These results can be coupled with hydrodynamic models to assess past and future changes in the quantity, quality, and distribution of suitable habitat for delta smelt. Future studies using field mesocosms or factorial laboratory experiments may shed additional light on the responses of delta smelt to multiple stressors. Nevertheless, future changes to the upper SFE environment are likely to increasingly limit the extent and quality of suitable habitats for delta smelt, while management actions have the potential to either mitigate or further exacerbate these imminent effects. Bold and creative strategies such as flow actions that distribute low-salinity habitat to cooler downstream regions, the establishment of thermal refuges, and population supplementation are likely needed to prevent the extinction of delta smelt in the wild.

Acknowledgements. We are grateful to our collaborators at the California Department of Fish and Wildlife (CDFW) and US Fish and Wildlife Service for providing delta smelt specimens from field collections for use in this study, and the Teh Lab at UC Davis who helped obtain, dissect, and archive specimens. We also thank the many past and present students and staff in the Otolith Geochemistry and Fish Ecology Laboratory at UC Davis (UCD) who contributed to fish dissections, otolith preparation, and growth analysis. Otolith archives were maintained in accordance with an approved CDFW Service Section 2081a Memorandum of Understanding to L.S.L., M.W., and J.A.H. Funding for this project was provided in part by grants from CDFW contracts E1183004, D1583004, and P1696005, and the US Bureau of Reclamation (USBR) contracts R13AP20022 and R17AC00129 to J.A.H., S. Teh, and L.S.L. Additional support was provided by the California Agricultural Experimental Station (UCD) grant number CA2D-WFB-2098-H to NAF and by the Delta Stewardship Council (DSC) via postdoctoral fellowships to M.W. (Grant No. 1167) and L.S.L. (Grant Nos. 2279, 5298). The content of this material and views described herein do not necessarily reflect the views and policies of the CDFW, USBR, DSC, or UCD, nor does mention of trade names or commercial products constitute endorsement or recommendation for use.

\section{LITERATURE CITED}

Anderson JT (1988) A review of size dependent survival during pre-recruit stages of fishes in relation to recruitment. J Northwest Atl Fish Sci 8:55-66

Baltz DM, Fleeger JW, Rakocinski CF, McCall JN (1998) Food, density, and microhabitat: factors affecting growth and recruitment potential of juvenile saltmarsh fishes. Environ Biol Fishes 53:89-103

Barrow J, Ford J, Day R, Morrongiello J (2018) Environmental drivers of growth and predicted effects of climate change on a commercially important fish, Platycephalus laevigatus. Mar Ecol Prog Ser 598:201-212

Bartoń K (2019) MuMIn: multi-model inference. R package, version 1.43.6. https://cran.r-project.org/package=MuMIn

* Beck MW, Heck KL, Able KW, Childers DL and others (2001) The identification, conservation, and management of estuarine and marine nurseries for fish and invertebrates. BioScience 51:633-641

Bennett WA (2005) Critical assessment of the delta smelt population in the San Francisco Estuary, California. San Francisco Estuar Watershed Sci 3:1-71

* Bever AJ, MacWilliams ML, Fullerton DK (2018) Influence of an observed decadal decline in wind speed on turbidity in the San Francisco Estuary. Estuar Coast 41: 1943-1967

* Blaber SJM, Blaber TG (1980) Factors affecting the distribution of juvenile estuarine and inshore fish. J Fish Biol 17 : 143-162 
Brett JR, Groves TDD (1979) Physiological energetics. In: Hoar WS, Randall DJ, Brett JR (eds) Fish physiology. Academic Press, New York, NY, p 279-352

Brown LR, Bennett WA, Wagner RW, Morgan-King T and others (2013) Implications for future survival of delta smelt from four climate change scenarios for the Sacramento-San Joaquin Delta, California. Estuar Coast 36: 754-774

Brown LR, Komoroske LM, Wagner RW, Morgan-King T, May JT, Connon RE, Fangue NA (2016) Coupled downscaled climate models and ecophysiological metrics forecast habitat compression for an endangered estuarine fish. PLOS ONE 11:e0146724

Campana SE (1990) How reliable are growth back-calculations based on otoliths? Can J Fish Aquat Sci 47:2219-2227

Campana SE, Jones CM (1992) Analysis of otolith microstructure data. Can Spec Publ Fish Aquat Sci 117:73-100

CDFG (California Department of Fish and Game) (2010) State and federally listed endangered and threatened animals of California. California Department of Fish and Game, State of California, The Natural Resources Agency, Sacramento, CA

* Cloern JE, Jassby AD (2012) Drivers of change in estuarinecoastal ecosystems: discoveries from four decades of study in San Francisco Bay. Rev Geophys 50:RG4001

* Cloern JE, Knowles N, Brown LR, Cayan D and others (2011) Projected evolution of California's San Francisco Bay-Delta-River System in a century of climate change. PLOS ONE 6:e24465

Cushing DH (1990) Plankton production and year-class strength in fish populations: an update of the match/ mismatch hypothesis. Adv Mar Biol 26:249-293

* Cyrus DP, Blaber SJM (1987) The influence of turbidity on juvenile marine fishes in estuaries. Part 2. Laboratory studies, comparisons with field data and conclusions. J Exp Mar Biol Ecol 109:71-91

* Cyrus DP, Blaber SJM (1992) Turbidity and salinity in a tropical northern Australian estuary and their influence on fish distribution. Estuar Coast Shelf Sci 35:545-563

Dahlke FT, Wohlrab S, Butzin M, Pörtner HO (2020) Thermal bottlenecks in the life cycle define climate vulnerability of fish. Science 369:65-70

Damon LJ, Slater SB, Baxter RD, Fujimura RW (2016) Fecundity and reproductive potential of wild female delta smelt in the upper San Francisco Estuary, California. Calif Fish Game 102:188-210

Dege M, Brown LR (2004) Effect of outflow on spring and summertime distribution and abundance of larval and juvenile fishes in the upper San Francisco Estuary. In: Feyrer F, Brown LR, Brown RL, Orsi JJ (eds) Early life history of fishes in the San Francisco Estuary and watershed. American Fisheries Society, Bethesda, MD, p 49-65

Feyrer F, Nobriga ML, Sommer TR (2007) Multidecadal trends for three declining fish species: habitat patterns and mechanisms in the San Francisco Estuary, California, USA. Can J Fish Aquat Sci 64:723-734

Feyrer F, Newman K, Nobriga M, Sommer T (2011) Modeling the effects of future outflow on the abiotic habitat of an imperiled estuarine fish. Estuar Coast 34:120-128

Fong S, Louie S, Werner I, Davis J, Connon RE (2016) Contaminant effects on California bay-delta species and human health. San Francisco Estuar Watershed Sci 14:5

Frank DF, Hasenbein M, Eder K, Jeffries KM, Geist J, Fangue NA, Connon RE (2017) Transcriptomic screening of the innate immune response in delta smelt during an Ichthyophthirius multifiliis infection. Aquaculture 473: 80-88

Gillanders BM, Elsdon TS, Halliday IA, Jenkins GP, Robins JB, Valesini FJ (2011) Potential effects of climate change on Australian estuaries and fish utilising estuaries: a review. Mar Freshw Res 62:1115-1131

* Green BS, Fisher R (2004) Temperature influences swimming speed, growth and larval duration in coral reef fish larvae. J Exp Mar Biol Ecol 299:115-132

Gregory RS (1993) Effect of turbidity on the predator avoidance behaviour of juvenile chinook salmon (Oncorhynchus tshawytscha). Can J Fish Aquat Sci 50:241-246

Grimaldo L, Feyrer F, Burns J, Maniscalco D (2017) Sampling uncharted waters: examining rearing habitat of larval longfin smelt (Spirinchus thaleichthys) in the Upper San Francisco Estuary. Estuar Coast 40:1771-1784

Kammock BG, Hobbs JA, Slater SB, Acuna S, Teh SJ (2015) Contaminant and food limitation stress in an endangered estuarine fish. Sci Total Environ 532:316-326

Hammock BG, Slater SB, Baxter RD, Fangue NA and others (2017) Foraging and metabolic consequences of semianadromy for an endangered estuarine fish. PLOS ONE 12:e0173497

*Hammock BG, Hartman R, Slater SB, Hennessy A, Teh SJ (2019) Tidal wetlands associated with foraging success of delta smelt. Estuar Coast 42:857-867

* Hasenbein M, Komoroske LM, Connon RE, Geist J, Fangue NA (2013) Turbidity and salinity affect feeding performance and physiological stress in the endangered delta smelt. Integr Comp Biol 53:620-634

* Herbst SJ, Marsden JE (2011) Comparison of precision and bias of scale, fin ray, and otolith age estimates for lake whitefish (Coregonus clupeaformis) in Lake Champlain. Lancet 37:386-389

*Hestir EL, Schoellhamer DH, Greenberg J, Morgan-King T, Ustin SL (2016) The effect of submerged aquatic vegetation expansion on a declining turbidity trend in the Sacramento-San Joaquin River Delta. Estuar Coast 39: 1100-1112

*Hill KD, Dauphinee TM, Woods DJ (1986) The extension of the practical salinity scale 1978 to low salinities. IEEE J Oceanic Eng 11:109-112

*Hinrichsen HH, Voss R, Huwer B, Clemmesen C (2010) Variability of larval Baltic sprat (Sprattus sprattus L.) otolith growth: a modeling approach combining spatially and temporally resolved biotic and abiotic environmental key variables. Fish Oceanogr 19:463-479

Hjort J (1914) Fluctuations in the great fisheries of northern Europe viewed in the light of biological research. Rapp P-V Reun Cons Int Explor Mer 20:1-228

Hobbs JA, Bennett WA, Burton JE, Baskerville-Bridges B (2007) Modification of the biological intercept model to account for ontogenetic effects in laboratory-reared delta smelt (Hypomesus transpacificus). Fish Bull 105:30-38

Hobbs JA, Moyle PB, Fangue N, Connon RE (2017) Is extinction inevitable for delta smelt and longfin smelt? An opinion and recommendations for recovery. San Francisco Estuar Watershed Sci 15:2

KHobbs JA, Lewis LS, Willmes M, Denney C, Bush E (2019) Complex life histories discovered in a critically endangered fish. Sci Rep 9:16772

Houde E (1989) Comparative growth, mortality, and energetics of marine fish larvae: temperature and implied latitudinal effects. Fish Bull 87:471-495 
Houde ED (2008) Emerging from Hjort's shadow. J Northwest Atl Fish Sci 41:53-70

Jain KE, Farrell AP (2003) Influence of seasonal temperature on the repeat swimming performance of rainbow trout Oncorhynchus mykiss. J Exp Biol 206:3569-3579

James NC, van Niekerk L, Whitfield AK, Potts WM, Götz A, Paterson AW (2013) Effects of climate change on South African estuaries and associated fish species. Clim Res $57: 233-248$

Jassby A, Kimmerer W, Monismith S, Armor C and others (1995) Isohaline position as a habitat indicator for estuarine populations. Ecol Appl 5:272-289

Jeffries KM, Connon RE, Davis BE, Komoroske LM and others (2016) Effects of high temperatures on threatened estuarine fishes during periods of extreme drought. J Exp Biol 219:1705-1716

Jeffries KM, Fangue NA, Connon RE (2018) Multiple sublethal thresholds for cellular responses to thermal stressors in an estuarine fish. Comp Biochem Physiol A Mol Integr Physiol 225:33-45

Kimmerer WJ (2002) Effects of freshwater flow on abundance of estuarine organisms: physical effects or trophic linkages? Mar Ecol Prog Ser 243:39-55

Kimmerer WJ, Gross ES, MacWilliams ML (2009) Is the response of estuarine nekton to freshwater flow in the San Francisco Estuary explained by variation in habitat volume? Estuar Coast 32:375-389

Knowles N, Cayan D (2002) Potential effects of global warming on the Sacramento/San Joaquin watershed and the San Francisco estuary. Geophys Res Lett 29:1891

Komoroske LM, Connon RE, Lindberg J, Cheng BS, Castillo G, Hasenbein M, Fangue NA (2014) Ontogeny influences sensitivity to climate change in an endangered fish. Conserv Physiol 2:cou008

Komoroske LM, Connon RE, Jeffries KM, Fangue NA (2015) Linking transcriptional responses to organismal tolerance reveals mechanisms of thermal sensitivity in a mesothermal endangered fish. Mol Ecol 24: 4960-4981

Komoroske LM, Jeffries KM, Connon RE, Dexter J, Hasenbein M, Verhille C, Fangue NA (2016) Sublethal salinity stress contributes to habitat limitation in an endangered estuarine fish. Evol Appl 9:963-981

*abonne M, Morize E, Scolan P, Laë R, Dabas E, Bohn M (2009) Impact of salinity on early life history traits of three estuarine fish species in Senegal. Estuar Coast Shelf Sci 82:673-681

Lankford TE, Targett TE (1994) Suitability of estuarine nursery zones for juvenile weakfish (Cynoscion regalis): effects of temperature and salinity on feeding, growth and survival. Mar Biol 119:611-620

Leggett WC, Deblois E (1994) Recruitment in marine fishes: Is it regulated by starvation and predation in the egg and larval stages? Neth J Sea Res 32:119-134

Lewis EL, Perkin RG (1981) The practical salinity scale 1978: conversion of existing data. Deep-Sea Res A Oceanogr Res Pap 28:307-328

K Lindberg JC, Tigan G, Ellison L, Rettinghouse T, Nagel MM, Fisch KM (2013) Aquaculture methods for a genetically managed population of endangered delta smelt. N Am J Aquacult 75:186-196

Kusardi RA, Hammock BG, Jeffres CA, Dahlgren RA, Kiernan JD (2020) Oversummer growth and survival of juvenile coho salmon (Oncorhynchus kisutch) across a natural gradient of stream water temperature and prey availability: an in situ enclosure experiment. Can J Fish Aquat Sci 77:413-424

Mac Nally R, Thomson JR, Kimmerer WJ, Feyrer F and others (2010) Analysis of pelagic species decline in the upper San Francisco Estuary using multivariate autoregressive modeling (MAR). Ecol Appl 20:1417-1430

*Mahardja B, Hobbs JA, Ikemiyagi N, Benjamin A, Finger AJ (2019) Role of freshwater floodplain-tidal slough complex in the persistence of the endangered delta smelt. PLOS ONE 14:e0208084

* Miller WJ, Manly BFJ, Murphy DD, Fullerton D, Ramey RR (2012) An investigation of factors affecting the decline of delta smelt (Hypomesus transpacificus) in the Sacramento-San Joaquin Estuary. Rev Fish Sci 20:1-19

* Moore JW, Moore IA (1976) The basis of food selection in flounders, Platichthys flesus (L.), in the Severn Estuary. J Fish Biol 9:139-156

*Morgan R, Sundin J, Finnøen MH, Dresler G and others (2019) Are model organisms representative for climate change research? Testing thermal tolerance in wild and laboratory zebrafish populations. Conserv Physiol 7: coz036

Morrongiello JR, Thresher RE (2015) A statistical framework to explore ontogenetic growth variation among individuals and populations: a marine fish example. Ecol Monogr 85:93-115

* Moyle PB, Herbold B, Stevens DE, Miller LW (1992) Life history and status of delta smelt in the Sacramento-San Joaquin Estuary, California. Trans Am Fish Soc 121: 67-77

* Moyle PB, Brown LR, Durand JR, Hobbs JA (2016) Delta smelt: life history and decline of a once abundant species in the San Francisco Estuary. San Francisco Estuar Watershed Sci 14:6

* Moyle PB, Hobbs JA, Durand JR (2018) Delta smelt and water politics in California. Fisheries 43:42-50

* Muhling BA, Gaitán CF, Stock CA, Saba VS, Tommasi D, Dixon KW (2018) Potential salinity and temperature futures for the Chesapeake Bay using a statistical downscaling spatial disaggregation framework. Estuar Coast 41:349-372

Nagelkerken I, Sheaves M, Baker R, Connolly R (2015) The seascape nursery: a novel spatial approach to identify and manage nurseries for coastal marine fauna. Fish Fish 16:362-371

NatureServe (2014) Delta smelt. Hypomesus transpacificus (errata version published in 2020). The IUCN Red List of Threatened Species 2014:e.T10722A174778740. https:// dx.doi.org/10.2305/IUCN.UK.2014-3.RLTS.T10722A1747 78740.en

Neubauer P, Andersen KH (2020) Thermal performance of fish is explained by an interplay between physiology, behaviour and ecology. Conserv Physiol 7:coz025

*Neuheimer AB, Thresher RE, Lyle JM, Semmens JM (2011) Tolerance limit for fish growth exceeded by warming waters. Nat Clim Change 1:110-113

Niklitschek E, Secor D (2009) Dissolved oxygen, temperature and salinity effects on the ecophysiology and survival of juvenile Atlantic sturgeon in estuarine waters: II. Model development and testing. J Exp Mar Biol Ecol 381:S161-S172

Nobriga ML, Sommer TR, Feyrer F, Fleming K (2008) Longterm trends in summertime habitat suitability for delta smelt, Hypomesus transpacificus. San Francisco Estuar Watershed Sci 6:1 
Pannella G (1971) Fish otoliths: daily growth layers and periodical patterns. Science 173:1124-1127

* Pedersen EJ, Miller DL, Simpson GL, Ross N (2019) Hierarchical generalized additive models in ecology: an introduction with mgcv. PeerJ 7:e6876

Peterson MS (2003) A conceptual view of environmenthabitat-production linkages in tidal river estuaries. Rev Fish Sci 11:291-313

Pörtner HO, Farrell AP (2008) Physiology and climate change. Science 322:690-692

Pörtner HO, Peck MA (2010) Climate change effects on fishes and fisheries: towards a cause-and-effect understanding. J Fish Biol 77:1745-1779

Reis G, Howard J, Rosenfield J (2019) Clarifying effects of environmental protections on freshwater flows to - and water exports from - the San Francisco Bay Estuary. San Francisco Estuar Watershed Sci 17:1

Robins PE, Skov MW, Lewis MJ, Giménez L and others (2016) Impact of climate change on UK estuaries: a review of past trends and potential projections. Estuar Coast Shelf Sci 169:119-135

Rose KA, Kimmerer WJ, Edwards KP, Bennett WA (2013a) Individual-based modeling of delta smelt population dynamics in the Upper San Francisco Estuary. I. Model description and baseline results. Trans Am Fish Soc 142: 1238-1259

Rose KA, Kimmerer WJ, Edwards KP, Bennett WA (2013b) Individual-based modeling of delta smelt population dynamics in the Upper San Francisco Estuary. II. Alternative baselines and good versus bad years. Trans Am Fish Soc 142:1260-1272

Rypel AL, Layman CA, Arrington DA (2007) Water depth modifies relative predation risk for a motile fish taxon in Bahamian tidal creeks. Estuar Coast 30: 518-525

Schismenou E, Giannoulaki M, Tsiaras K, Lefkaditou E, Triantafyllou GS, Somarakis S (2014) Disentangling the effects of inherent otolith growth and model-simulated ecosystem parameters on the daily growth rate of young anchovies. Mar Ecol Prog Ser 515:227-237

Schismenou E, Palmer M, Giannoulaki M, Alvarez I, Tsiaras K, Triantafyllou G, Somarakis S (2016) Seasonal changes in otolith increment width trajectories and the effect of temperature on the daily growth rate of young sardines. Fish Oceanogr 25:362-372

Editorial responsibility: Jana Davis,

Annapolis, Maryland, USA

Reviewed by: C. Denechaud, B. Herbold, B. I. Ruttenberg
Scoville C (2019) Hydraulic society and a 'stupid little fish': toward a historical ontology of endangerment. Theory Soc 48:1-37

Shima JS, Swearer SE (2019) Moonlight enhances growth in larval fish. Ecology 100:e02563

Smith WE, Newman KB, Mitchell L (2020) A Bayesian hierarchical model of postlarval delta smelt entrainment: integrating transport, length composition, and sampling efficiency in estimates of loss. Can J Fish Aquat Sci 77: 789-813

Speers-Roesch B, Norin T (2016) Ecological significance of thermal tolerance and performance in fishes: new insights from integrating field and laboratory approaches. Funct Ecol 30:842-844

* Swanson C, Reid T, Young PS, Cech JJ Jr (2000) Comparative environmental tolerances of threatened delta smelt (Hypomesus transpacificus) and introduced wakasagi (H. nipponensis) in an altered California estuary. Oecologia 123:384-390

* Thomson JR, Kimmerer WJ, Brown LR, Newman KB and others (2010) Bayesian change point analysis of abundance trends for pelagic fishes in the upper San Francisco Estuary. Ecol Appl 20:1431-1448

* Tigan G, Mulvaney W, Ellison L, Schultz A, Hung TC (2020) Effects of light and turbidity on feeding, growth, and survival of larval delta smelt (Hypomesus transpacificus, Actinopterygii, Osmeridae). Hydrobiologia 847:2883-2894

US Fish and Wildlife Service (1993) Determination of threatened status for the delta smelt. Fed Regist 58:12854-12864

* Weisberg S, Spangler G, Richmond LS (2010) Mixed effects models for fish growth. Can J Fish Aquat Sci 67:269-277

*Welch TJ, van den Avyle MJ, Betsill RK, Driebe EM (1993) Precision and relative accuracy of striped bass age estimates from otoliths, scales, and anal fin rays and spines. N Am J Fish Manag 13:616-620

*Wenger AS, Whinney J, Taylor B, Kroon F (2016) The impact of individual and combined abiotic factors on daily otolith growth in a coral reef fish. Sci Rep 6:28875

Wood SN (2017) Generalized additive models: an introduction with R, $2^{\text {nd }}$ edn. Chapman and Hall/CRC, New York, NY

Xieu W, Lewis LS, Zhao F, Fichman RA and others (in press) Experimental validation of otolith-based age and growth reconstructions across multiple life stages of a critically endangered estuarine fish. PeerJ

Submitted: February 15, 2021

Accepted: July 30, 2021

Proofs received from author(s): October 4, 2021 